University of Nebraska - Lincoln

DigitalCommons@University of Nebraska-Lincoln

PreColumbian Textile Conference VIII /

Jornadas de Textiles PreColombinos VIII (2019)

Centre for Textile Research

$6-2020$

\title{
Los tocapus de Llullaillaco
}

Beatriz Carbonell

Follow this and additional works at: https://digitalcommons.unl.edu/pctviii

Part of the Art and Materials Conservation Commons, Fiber, Textile, and Weaving Arts Commons, Indigenous Studies Commons, Latin American Languages and Societies Commons, Museum Studies Commons, and the Other History of Art, Architecture, and Archaeology Commons

This Article is brought to you for free and open access by the Centre for Textile Research at DigitalCommons@University of Nebraska - Lincoln. It has been accepted for inclusion in PreColumbian Textile Conference VIII / Jornadas de Textiles PreColombinos VIII (2019) by an authorized administrator of DigitalCommons@University of Nebraska - Lincoln. 


\title{
Los tocapus de Llullaillaco
}

\author{
Beatriz Carbonell \\ Universidad Fasta Patagonia Argentina \\ beatriz.carbonell17@gmail.com
}

\section{Resumen}

En el hallazgo de Llullaillaco los motivos de tocapu y cumbi se reiteran en importantes textiles que visten a los niños ofrendados y en otros en forma de miniatura vistiendo a las estatuillas que conforman el ajuar.

Tanto las miniaturas antropomorfas de metal (oro y plata) como las de mullu (spondylus) están vestidas con uncu (túnica), yacolla (manto) y llautu (o vincha) y llevan una bolsa o chuspa con los mismos diseños que las prendas que visten los niños.

Nuestra comprensión del significado de tocapu se basa en cómo ha sido descrito por los cronistas, asociado a veces íntimamente con el textil y otras a la narrativa, aunque no conozcamos aún un sistema que nos permita descifrarlo.

Ha sido utilizado en forma radicalmente diferente: política, cultural y religiosamente.

Se identifica por tener a veces un patrón repetitivo y otras no, con formas abstractas, compuestos por figuras geométricas y líneas organizadas que representan un sentido.

Es transhistórico, podemos hallarlo hoy en diferentes regiones vinculado a la arquitectura, los símbolos rituales, al Inca, y en siglos posteriores influenciando vestimentas y mantos ricamente ornamentados (por ejemplo, en el período colonial).

Palabras claves: Sacrificios de Llullaillaco, capac qocha, tocapu, cumbi, simbolismo textil

\section{Abstract}

In the Llullaillaco contexts, the tocapu and cumbi designs are repeated in significant textiles worn by the sacrificed children and on the miniatures worn by the figurines that make up the offerings.

Both the anthropomorphic metal miniatures (in gold and silver) and those of mullu (spondylus) are dressed with an uncu (tunic), yacolla (cloak) and llautu (headband). They carry a bag or chuspa with the same patterns as the clothes the children are wearing.

Our understating of the meaning of tocapu is based on the descriptions of chroniclers. These descriptions are sometimes intimately linked to the idea of textiles, and at other times to the narrative of the designs, although we do not know yet a system that allows us to decipher its real meaning. Tocapu has been used radically differently in political, cultural and religious fields.

They are defined by having a repetitive pattern sometimes, though not repetitive at other times, with abstract shapes composed of geometric figures and organized lines that represent a meaning.

Tocapu is transhistorical, we can find it today in different regions linked to architecture, ritual symbols, to the Inca, and in later centuries influencing richly ornamental clothes and cloaks (for example, in the colonial period).

Keywords: Llullaillaco sacrifices, capac cocha, tocapu, cumbi, textile symbolism

\section{Résumé}

Dans les contextes Llullaillaco, les motifs tocapu et cumbi se répètent dans les textiles importants portés par les enfants sacrifiés ainsi que dans les éléments miniatures que vêtent les statuettes qui composent l'offrande.

Tant les miniatures anthropomorphes en métal (or et argent) que celles en mullu (Spondylus) sont revêtues d'un uncu (tunique), d'une yacolla (manteau) et d'un llauto (bandeau) et ont un sac ou chuspa avec les mêmes motifs que les vêtements que portent les enfants.

DOI: $10.32873 /$ unl.dc.zea.1210

Published in PreColumbian Textile Conference VIII / Jornadas de Textiles PreColombinos VIII, ed. Lena Bjerregaard and Ann Peters

(Lincoln, NE: Zea Books, 2020). https://digitalcommons.unl.edu/zeabook/ 
Notre compréhension de la signification des tocapu repose sur la façon dont ils sont décrits par les chroniqueurs, parfois en association étroite avec les textiles, et d'autres fois selon l'aspect narratif des figures, bien que nous ne connaissions pas encore de système permettant de véritablement déchiffrer leur sens.

Les tocapu ont été utilisés de manière totalement différente : politique, culturelle ou religieuse. Ils s'identifient par la présence d'un modèle répétitif occasionnel, comprenant des formes abstraites, composées par des figures géométriques et des lignes organisées évocatrices d'un sens précis.

Les tocapus sont transhistoriques, nous pouvons les trouver de nos jours dans différentes régions liées à l'architecture, aux symboles rituels, au pouvoir, à l'Inca, et dans les siècles suivants influençant les vêtements et les tuniques richement décorés (par exemple, à l'époque coloniale).

Mots-clés: Sacrifices de Llullaillaco, capac cocha, tocapu, cumbi, symbolisme textile

\section{Introdución}

\section{El hallazgo}

El volcán Llullaillaco está ubicado a latitud $24^{\circ} 43^{\prime} 05^{\prime \prime} \mathrm{S}$ y en longitud $68^{\circ} 32^{\prime} 10^{\prime \prime} \mathrm{O}$, en la Cordillera de los Andes, entre Argentina y Chile y mide 6739 metros sobre el nivel del mar.

En marzo de 1999, la Doctora Constanza Ceruti y el Dr. Johan Reinhard en el marco de una campaña arqueológica realizaron relevamientos y sondeos de la base del volcán (4.90o mts) con recuperación de material óseo en tumbas huaqueadas, explorando hasta llegar al conjunto de ruinas (6550 m).

En la plataforma se hallaron tres enterratorios con sus respectivos ajuares (173 piezas y artefactos) con recuperación de material óseo en tumbas huaqueadas.

Los elementos en el hallazgo arqueológico de Llullaillaco constituyen una de las colecciones incas mejor conservadas. (Ceruti 2015) quien indica que tres niños y sus ajuares asociados fueron descubiertas y recuperadas para su estudio y preservación, durante excavaciones por ella co-dirigidas en el noreste de Argentina.

En el contexto de una ceremonia capac hucha los niños ofrendados presentaban características de preservación especiales a pesar de llevar más de 500 años en su hábitat.

Estos sacrificios fueron realizados a causa de catástrofes, la muerte del Inca, o para auspiciar la fertilidad.

Molina (1989) destaca los sacrificios de niños traídos al Cuzco desde diferentes regiones del Imperio, participando primero de la celebración de los rituales estatales y llevados luego a sacrificio de acuerdo con el rango del pueblo, sus padres o jefes, delegados a las guacas más importantes y luego a todas las guacas y montañas sagradas del territorio, honrando así a las provincias ya que ninguna debía ser olvidada porque ello sería visto como una falta o deuda (hucha) del propio Inca con las jerarquías locales.

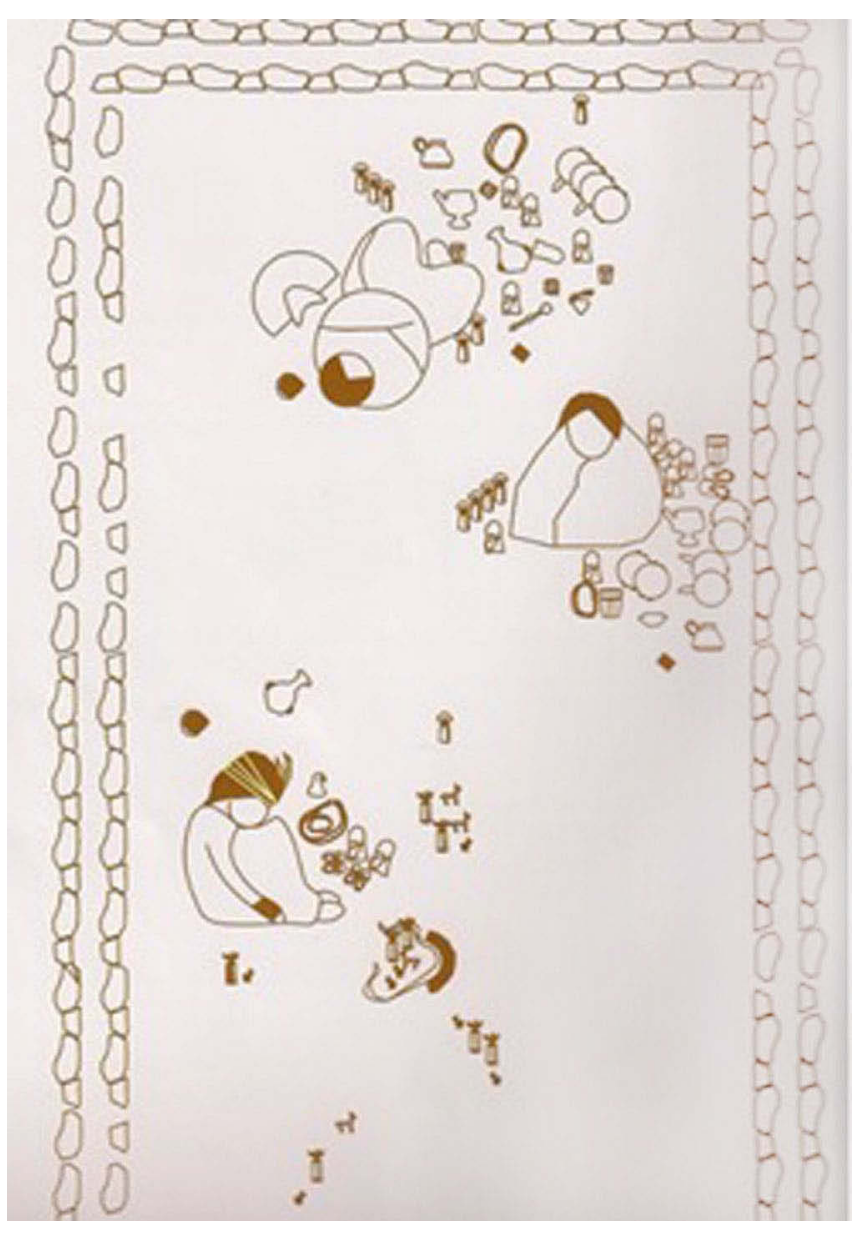

Figura 1. Dibujo que muestra la distribución del hallazgo de Llullaillaco, los tres niños con sus enseres enterratorios según fueran hallados. MAAM Museo Arqueológico de Alta Montaña, Ciudad de Salta, Argentina 


\section{Orden y Sistema ritual}

En las culturas preincaicas se manifiesta la importancia del agua y su distribución, pero en ningún lugar con tanta complejidad y elegancia como en el Cuzco donde el Inca integra las unidades de administración de las poblaciones relacionándolas directamente con la geografía hidráulica, creemos que por ello se elige Llullaillaco como guaca de ofrenda.

\section{Dimensión espacio-temporal}

Algunos aspectos de la dimensión espacial en Llullaillaco estarían determinados por su ubicación geográfica que ya describimos, por su condición de montaña más alta y volcán, por su situación en el sistema de ceques e hidrografia; estableciendo su posición concéntrica y de expansión exterior del Estado Inca hacia otros territorios, en este caso hacia el sur.

Ubicada en la región del hurin (mundo de abajo) la ofrenda en esa montaña manifiesta la necesidad del Inca de unir el hanan (mundo de arriba) con el hurin, es decir el centro ceremonial de Cuzco con el Collasuyu y a través de la capacocha o capac hucha, integrarlo a las otras regiones del Tawantinsuyu, a modo de cohesión territorial.

J. Sherbondy (1987) indicaba que las líneas radiales o ceques cumplían múltiples funciones, entre ellas señalar las fuentes de agua para las acequias de un pueblo y ligarlas mental y ritualmente a un punto central de la población por medio de líneas.

El pueblo de Socaire en el mapa une desde su sitio ceremonial para los ritos, con los cerros sagrados que según la cosmología inca lo proveen del agua para su canal.

\section{Llullaillaco: su condición de guaca}

Guaca o huaca o waka como aparece en diferentes escritos, Gonzalez Holguin (2007 [1608]) lo tradujo como "ydolos, figurillas de hombres y animales".

Otros autores refieren a guaca con diferentes significados espaciales:

Wak'a, guaca o huaca Ricardo lo traduce "ídolo, adoratorio, o cualquier cosa señalada por la naturaleza"

y Szeminski (1987) propone: "muchos de los significados (de guaca) muestran una asociación muy fuerte con tierra o con lugar (esconder debajo de la tierra, lugar peligroso, peña en forma especial (...), laguna) con el mundo de abajo en general”

Huaccap nam "Passo, o lugar peligroso, o espantable” Gonzalez Holguin 2007 [1608]

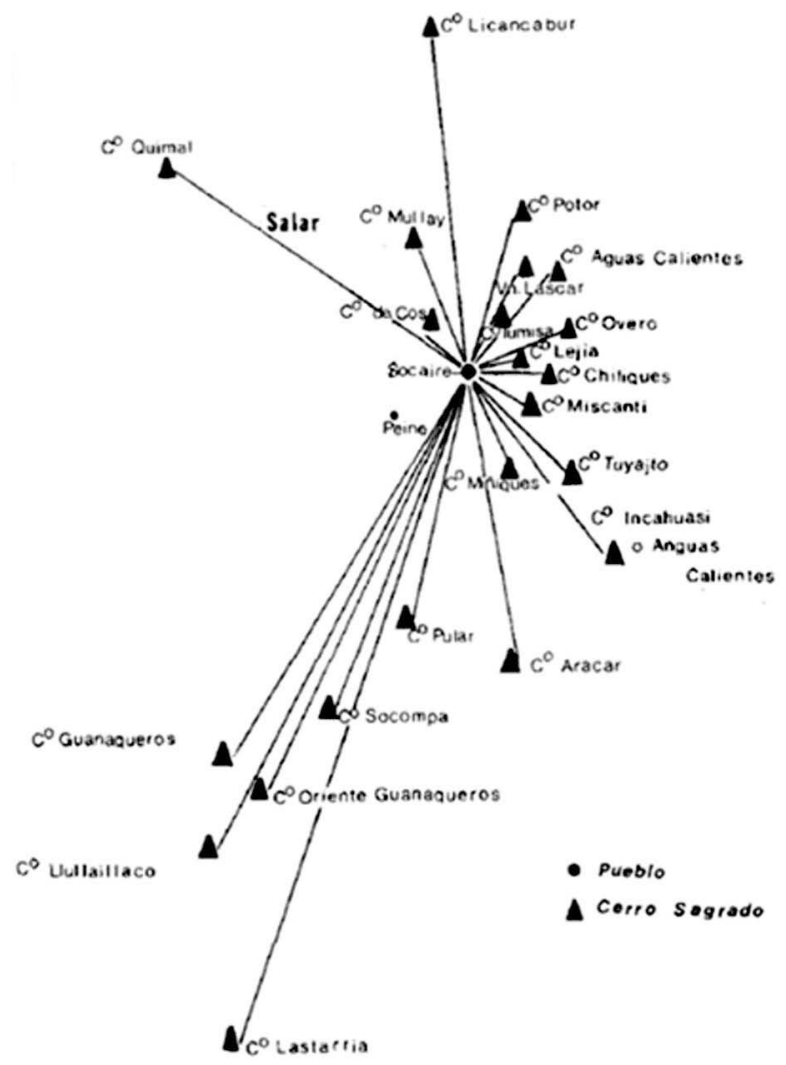

Figura 2 Mapa de Jeanette Sherbondy (1987), sistema de distribución hidraúlica en sitios de alta montaña, los que constituían probables guacas en cerros del Collasuyu, en el mismo se destaca el Volcán de Llullaillaco como Cerro Sagrado.

Muchos son los cerros que envían el agua al sistema de irrigación de Socaire, entre ellos el Llullaillaco.

La toponimia actual y sus significaciones lingüísticas permiten asociar el nombre de este río con el volcán más imponente de todo ese territorio, el Llullaillaco.

Su nombre, también quechua, significa "agua" o "aguas mentirosas". Se establecía que los volcanes y sus santuarios tenían profundas connotaciones no sólo en lo ritual sino también como elementos organizadores del espacio simbólico, social, político y económico.

El incumplimiento del grupo o del individuo de sus obligaciones frente a la guaca crea un estado de hucha con consecuencias de enfermedades, sequía, infortunios sobre las personas o poblaciones, por ello hasta el Inca debía respetar los contratos establecidos a través de las guacas.

Elena Phipps (2017) en importante trabajo sobre tradición en textiles andinos detalla que otros objetos fueron considerados wak'as o sagrados, o que contienen poder y fueron descriptos en Polo Ondegardo en el siglo XVI (d.1575); como ciertas mazorcas de maíz especiales llamadas 
zaramama que estaban envueltos en mantos de tela o vestidos con prendas de mujer.

\section{Capacocha o capac hucha}

Los términos capacocha o capac hucha describen un ritual estatal en Cuzco y en distintas regiones del Tawantinsuyu, expresando servicios recíprocos entre:

los individuos, el Inca y lo sobrenatural.

Varios cronistas describieron la función de los textiles identificando lugares sagrados y vistiendo las ofrendas, los ídolos y parafernalia que rodean a los mismos en las cumbres altas de guacas sagradas.

Hernández Príncipe (1923 [1622] pag 6o-61) "escribiré lo que de ello tengo entendido que es verdad.

Y así dicen que se tenía por costumbre en el Cuzco por los reyes que cada año hacían venir [a] aquella ciudad a todas las estatuas y bultos de los ídolos que estaban en las guacas, que eran los templos donde ellos adoraban; las cuales eran traídas con mucha veneración por los sacerdotes y "camayos" de ellas, que es nombre de guardianes, y como entrasen en la ciudad, eran recibidas con grandes fiestas y procesiones y aposentadas en los lugares que para aquello estaban señalados y establecidos; y habiendo venido de las comarcas de la ciudad y aun de la mayor parte de las provincias número grande de gente, así hombres como mujeres, el que reinaba acompañado de todos los Ingas y orejones, cortesanos y principales de la ciudad..."

Cieza de Leon en el "Señorío de los Incas" ([1553] 1986-Cap. XXIX).

Guaman Poma (1987) refiere que en las fiestas Capac Ynti Raymi [festejo del señor sol] (vacas, ídolos 265[267] ) llamando capac ocha a los sacrificios humanos y ofrendas:

"De cómo ordenó bestidos y rropa de sus dioses uacas le llaman capac ocha [afrenta al Inka, sacrificios humanos] Lo hazían de cunbi [tejido fino] y de auasca [corriente] y de su baxilla de oro y plata y de uarro y mullo [concha] y cobre y donde soterraua y tenía pastos y sementeras y ganados y yndios llamados yana yaco del sol y de las uacas ýdolos deste rreyno."

En el ritual capac hucha el soberano Inca podía conceder a cada grupo social del imperio o a su curaca (sacerdote) el privilegio de enviar al Cusco o cualquier otro centro ritual un niño sin mancha de nacimiento.

Allí el niño sería ofrendado o desde allí se reenviaba a otro lugar, incluso a su lugar de origen para ser ofrendado.

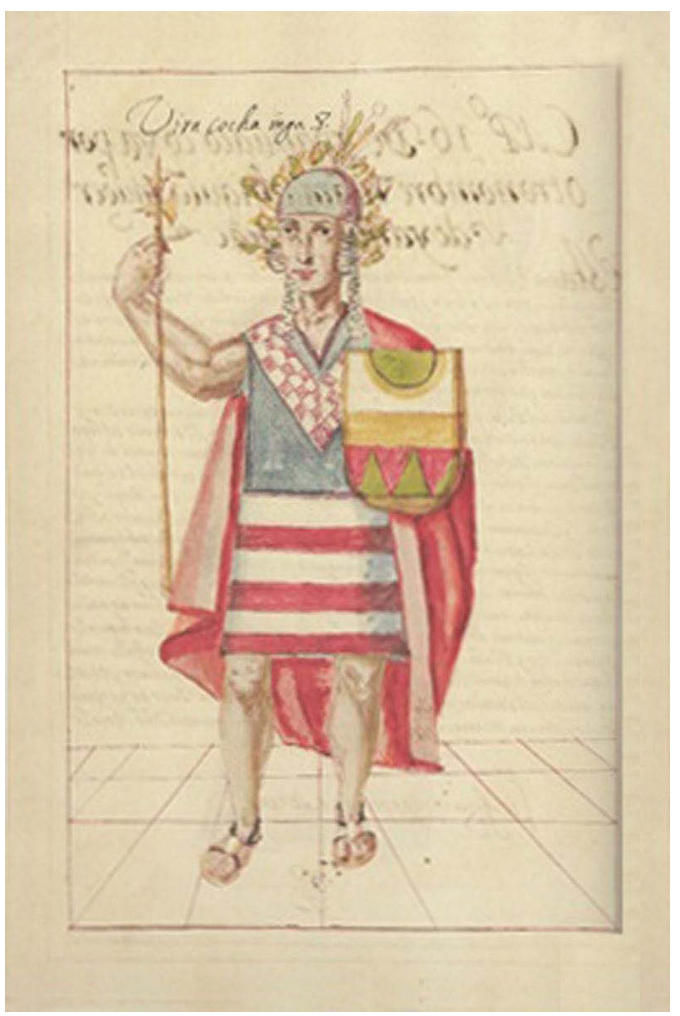

Figura 3 Viracocha Inca (en Murua Paul Getty publicación 2008) Octavo soberano Inca, conquistó territorios alrededor de Cusco iniciando el Imperio; amplió la producción textil y distribuyó los tocapus en la ropa de los nobles extendiendo su difusión.

Algunos cronistas ponen de manifiesto la dimensión de capacocha como un rito geográfico espacial y la entrega de una persona elegida como capac hucha a su lugar final (Molina 1989, Albornoz 1989, Juan Ossio Códice Murúa 2004).

Otra finalidad de capac hucha era consolidar el apoyo a través de sus guacas de todas las regiones del Incanato, el ritual como un medio de comunicación entre el sacrificado y el sacrificante; entre el Inca con sus poblaciones y de cada uno de ellos con sus divinidades.

\section{Las ofrendas}

"Relación" 1923 [1622] Hernández Principe entiende que existieron dos tipos de capacocha:

-la capacocha estatal inca,

-y los sacrificios de tipo local en los Andes

Norcentrales, en el espacio de grupos étnicos distintos.

La ceremonia en el Llullaillaco evidencia características que la muestra como un ofrecimiento de carácter real, no local, de las que se llevaban a cabo para la protección contra la adversidad del Inca, con carácter de procesión sagrada considerando la riqueza y diversidad regional de sus ofrendas. 


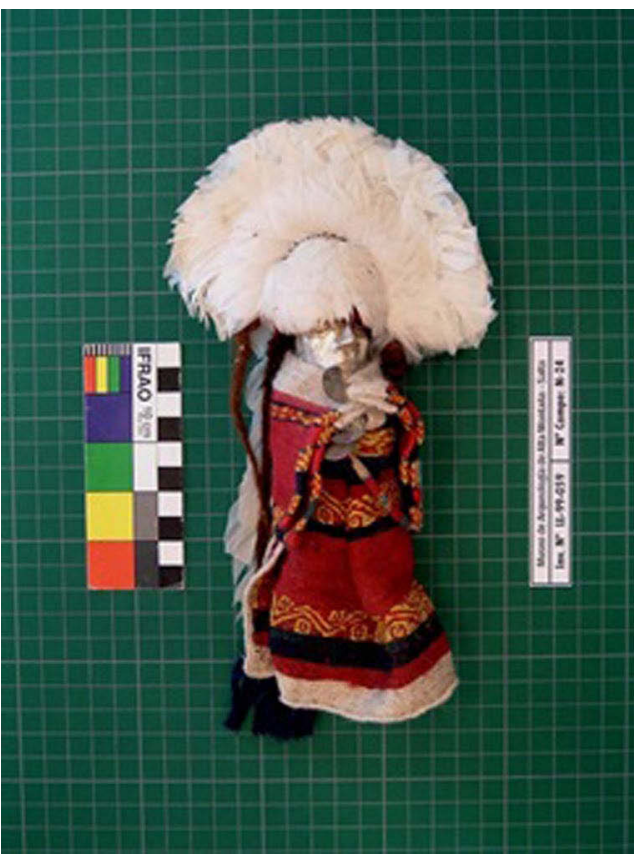

Figura 4a. Figura de plata hallada junto a la doncella, vistiendo su tocado de plumas blancas, representándola en vestimenta y detalles en miniatura.

Es que el término capacocha o capac hucha podría ser aplicado también al textil que identificaba y representaba una guaca; pudiendo incluso reemplazarla. Algunos ejemplos tratan de tejidos encontrados con las momias, los investigadores que han descrito estas circuntancias (Ceruti 2003; Gentile Lafaille 2010; Reinhard and Ceruti 2006) dan cuenta de ello y describen que en varios casos se colocan uncus al lado de la momia, frecuentemente estandarizados con tejidos de tocapus, descubiertos y preservados en diferentes hallazgos.

Los tocapus y telas cumbí se reiteran en textiles de gran dimensión y en forma de miniatura, diversos diseños en marcos o cuadrados utilizados en el arte Inca, tal vez y siempre de todas maneras como un sistema semántico.

Dicen que fue Viracocha Inca (octavo inca) quien difundió el diseño de tocapu en todas las regiones del Incanato (Margarita Gentile 2009).

\section{Tocapus y cumbí}

El significado de tocapu se basa en cómo ha sido descrito por los cronistas y en la actualidad por los numerosos investigadores que trabajan este tema.

Por ejemplo Martín de Murúa [1616] escribe: "el vestido que ordinariamente usaba, era una camisa de cumbí labrada, obra de las ñustas que lo hilaban sutilísimamente para

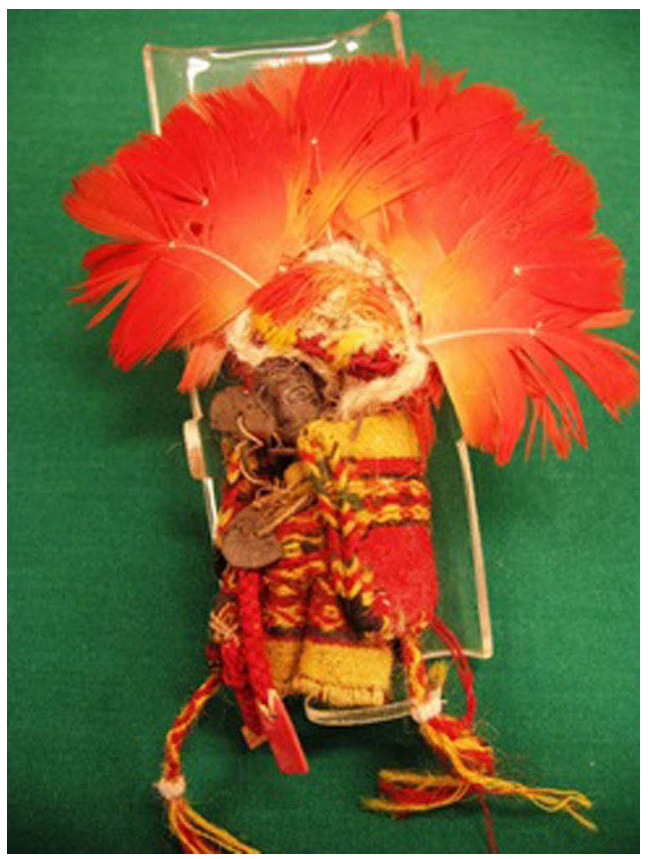

Figura 4b. Figura de plata en miniatura con vestimenta textil y diseño cumbí, lleva tocado de plumas. Posee terminaciones de spondylus en los cordones hallada junto a la doncella. Archivo Museo MAAM Salta Argentina

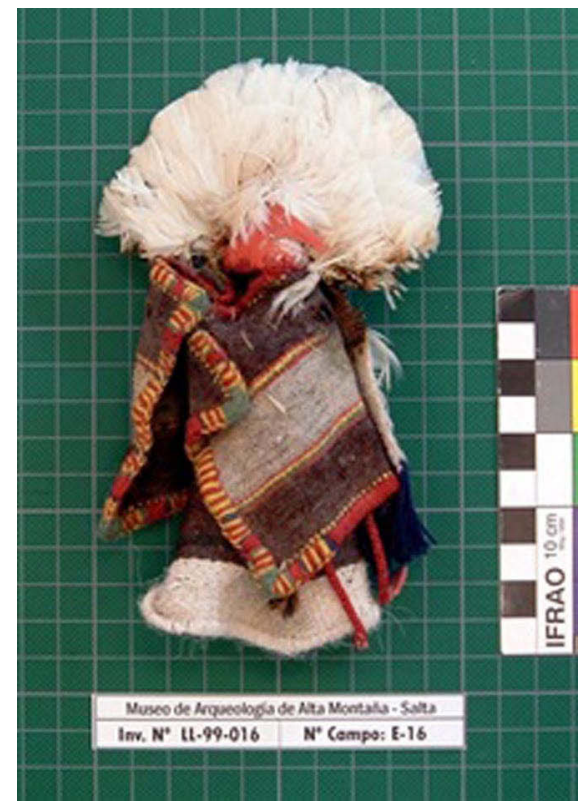

Figura 5. Idolo vestido con textiles y con tocado en miniatura. hallada junto a la niña del rayo textil en color gris, poco común en esta figura con terminaciones en hilos de color rojo amarillo verde y negro.

tejer los vestidos o uncus del Inca, esculpiendo en ellas maravillosas labores de tocapo, ellos dicen que significa diversidad de labores". 


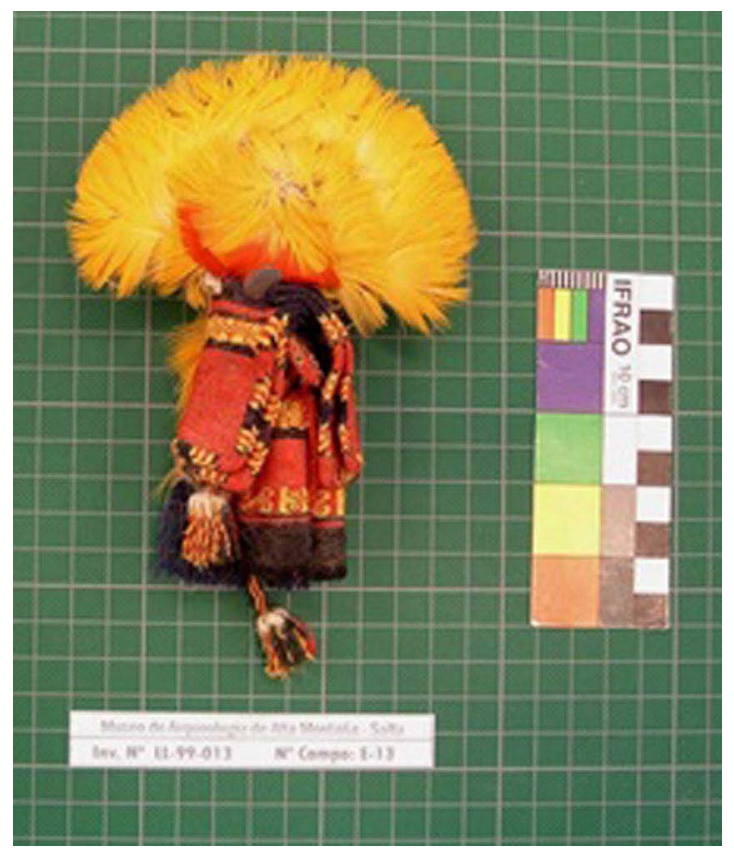

Figura 6a. Figura de plata con tocado de plumas amarillas, con diseño de llave inca en el ruedo textil

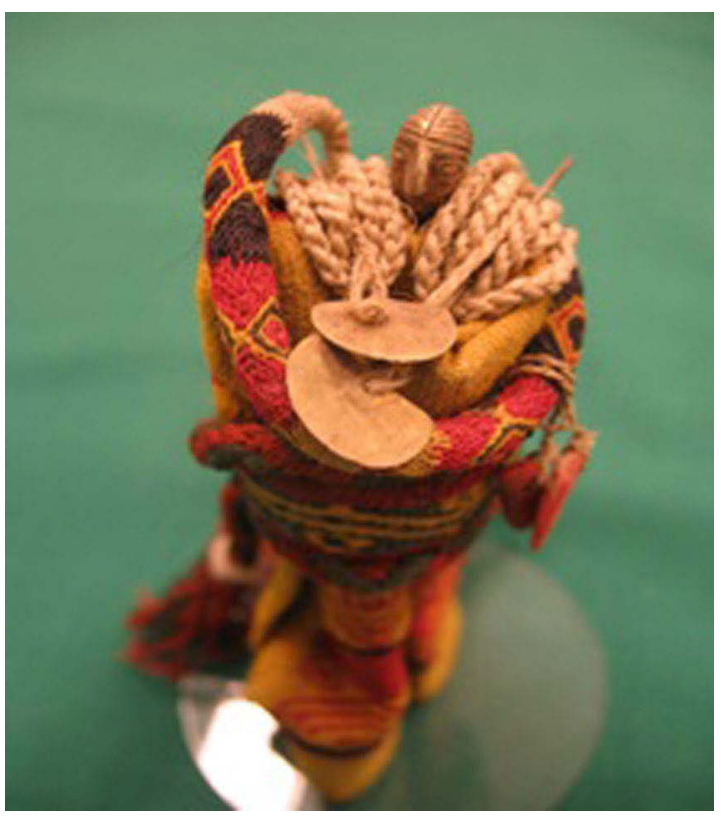

Figura 6b. Figura de plata con parafernalia, tupus de plata y diseño diamante en el textil

Cerrón Palomino (2008: 108-109) citado en Cummins (2011) traza la etimología del término tocapu, expresando que significa primero el poder y la riqueza de reyes incas y luego viene el concepto de elegancia y distinción que se expresa en la forma material de un textil.

Actualmente el tocapu como representación de textos completos ha inspirado indirectamente el trabajo de un número de académicos que han buscado y buscan darle diversos significados Frame (2005,2007); Gentile L. (2008, 2009a ); Silverman (1999, 2015); Ziólkowski et al. (2008).

Victoria de la Jara (1975) afirmaba que se trataba de una escritura logográfica en la que cada motivo representaba una palabra completa, en una representación gráfica del lenguaje similar a ideogramas chinos.

Mary Frame (1994) analiza la estructura y se refiere luego a un modo de codificar tocapu: "la presencia de estructuras textiles ampliamente complejas y un sistema de imágenes basado en ellas sugiere que los antiguos pobladores hicieron abstracción de un código, usando las distinciones de estructuras textiles para transmitir distinciones en cuanto a significado. La fibra puede ser el medio, pero el contenido de tal código podría ser más amplio.

Las distinciones de simetría, número, color, orden, y dirección podrían efectivamente describir conceptos espaciales y sincronizarse con conceptos temporales."

Se refiere a la forma en que el significado puede expresar es decir la lógica que dirige y ordena ese código.

Utilizando valores geométricos define tocapu (2009 editado 2014) como marcos diagramáticos de relaciones y que éstas están incorporadas en propiedades tales como simetría, dirección, número, concentricidad, color y brillo. Las propiedades y formatos mediante los cuales se organizan son semi-matemáticos y la combinación de propiedades tiene un potencial para expresar gráficamente ideas relacionales.

Zuidema (1991) ofrece una definición que resume bien lo que es un conjunto general de propiedades comunes: al tocapu

"Tocapu cuadrado y sobre todo abstractos signos utilizados en textiles incas y en otros medios." formaron parte del complicado sistema de representación aunque nadie ha informado de ello directamente (Zuidema 1991: 151)

Destaca dos conceptos: expresa la suposición de que el tocapu es un sistema gráfico aunque ningún cronista ha escrito nada que sugiera esto y en segundo lugar define la forma del tocapu como primordialmente abstracta.

La abstracción geométrica es una descripción más precisa ya que la mayoría de los textiles están compuestos por figuras-diamantes, cuadrados, rectángulos, líneas diagonales y horizontales, todas ellas organizadas dentro de un cuadrado, romboide o rectángulo bordeado.

El encuadre de cada composición geométrica permite que el tocapu sea visto simultáneamente como entidad individual y como elemento en relación con otros elementos.

Las características definitorias del tocapu no se han descrito aun completamente, no sabemos si existe una sola síntaxis que los ordena, si el dibujo en blanco y negro de Guaman Poma lo representan, creeríamos que el color no 
es necesario para decodificarlos como formas geométricas? (Cummins 2011).

E. Phipps (2017) descubre que hay mucho que examinar en la relación entre telas y prendas asociadas con actividades sagradas en los Andes. Podemos ver que sus materiales y colores forman una parte integral del uso y el significado, nos indica. La agencia de el paño generada en el contexto de su materialidad, ameritan un estudio más profundo.

\section{El tocapu como transhistórico}

La transhistoricidad es la cualidad de mantener a lo largo de la historia humana, no sólo dentro del marco de referencia de una forma particular de sociedad, ni en una etapa particular del desarrollo histórico.

Se dice que una entidad o concepto que tiene transhistoricidad se mantiene en una época y puede estar completamente ausente o llevar implicaciones opuestas en otra.

Las composiciones pictóricas, la aparición de narrativas pictóricas en el período colonial pueden haber sido una expresión de lo que el tocapu y el/ los objetos sobre los que aparecen pudieron comunicar antes y después de la conquista.

Esta relación entre tocapu y la imagen pictórica es probablemente contextual.

Frame (2007) indica que el modo nativo de expresión gráfica, usado por Guarnan Poma, transmite algunas informaciones que no están expresadas en el texto escrito español.

El tema del tucapu, el código gráfico de los incas, está tan ausente del texto en castellano que un estudio sugirió que éste quedaba oculto a propósito y retenía informaciones sobre el tucapu (Cummins 1997: 258-60). También muestra cambios en quienes visten ropas con tucapu en tiempos anteriores y después de la conquista.

Catherine Julien (2000) destaca la función heráldica del tocapu, y que las tunicas cumbí con diversos colores y motivos representan las provincias que poseía el Inca.

David de Rojas y Silva (2008) en un minucioso trabajo que analiza y determina el uso y función del tocapu, concluye que los mismos conforman una seriación documental heráldica, clasificando a las familias mediante símbolos gentilicios.

Este autor considera que los tocapu hallan su continuación cultural en el pallay de los tejidos actuales, que con adornos adicionales y contemporáneos precisan una identificación tradicional de comunidades campesinas.

Los motivos tocapus perduran en el imaginario de los pobladores, actualmente tejen imágenes derivadas ellos, aunque no conozcan los nombres de los diseños; porque los hayan olvidado o sustituido, aun asi las estructuras de los

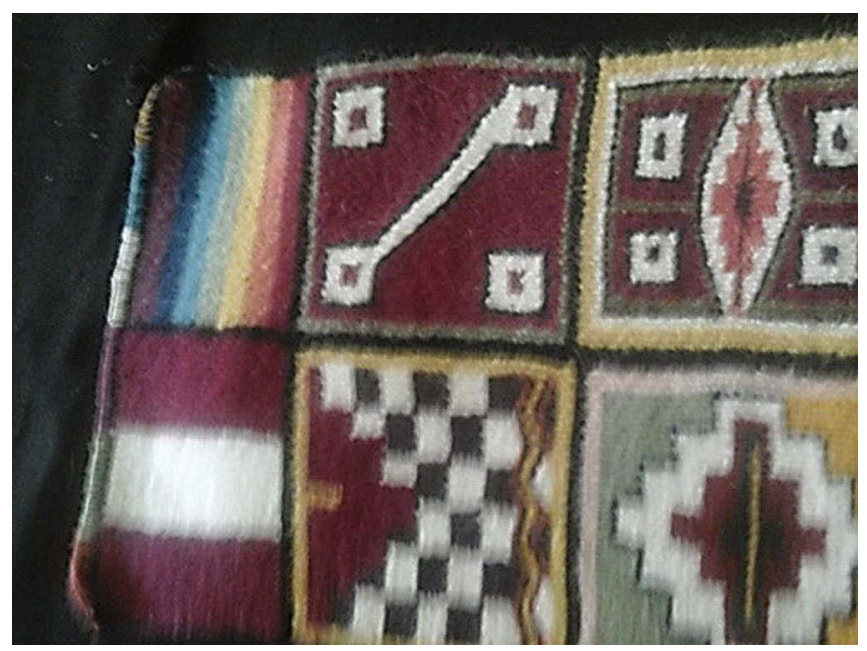

Figura 7. Tapiz tejido actualmente en Pitumarca (foto Carbonell 2016), reproduce figuras de tocapu tejidas recientemente, representando la parafernalia inca y agrupados según diseño y colores propuestos por el tejedor

textiles son entendidas detalladamente, también por quienes nunca han tejido.

\section{Tocapu: elemento comunicacional}

Gentile (2009b) argumenta que en las crónicas y diccionarios tempranos tocapu nombraba un tipo de trabajo textil de alta calidad "inventado" por el Inca Viracocha.

Guarnan Poma en el dibujo tucapu, representa gobernantes incas, sus esposas y nobles vistiendo los diseños geométricos en su vestimenta tejida. Haciendo esto, transmite informaciones importantes sobre el código gráfico en general, sin usar palabras, puede decirse que inventó un estilo híbrido de ilustración fusionando dos tradiciones gráficas.

Eeckhout et Danis (2004) en su investigación sobre los tocapus reales en Guaman Poma; determinan que pueden considerarse como una especie de heráldica incaica representados en uncus y queros. Siendo probable que los tocapus sí constituyen una forma de comunicación gráfica que abarca otros campos además de la heráldica: la toponimia, jerarquías de rango social y militar, símbolos para fiestas y períodos del año, culto a las divinidades.

Cummins (2004; 2011) en su trabajo de análisis del tucapu plantea la posibilidad de que a través de ellos se expresaran conceptos abstractos, cuyo significado simbólico debería entenderse de forma contextual. Este estudio tendrá que mirarse más allá de la interpretación de cualquier tocapu como signo existente en un contexto específico, como los de queros o cerámicos; será un estudio que considerará el rango histórico y la diversidad para llegar a una descripción funcional. 
Cummins (2011) plantea si el tocapu realmente un sistema histórico de notación? O es meramente idiosincrásico y básicamente mnemónico e históricamente específico, como lo sugirió George Kubler quien creía que el despliegue continuo de los tocapu en el período colonial era decorativo y que había perdido toda capacidad para transmitir significado.

Frame (2009) lo analiza como un tipo de código que opera en un nivel más abstracto, aunque expresa relaciones de carácter social con los pobladores, diseños que se reiteran y que actualmente pueden ser comprendidos aún por los nativos que no saben tejer.

El código de tocapu difiere notablemente de los sistemas de escritura antiguos que han sido descriptos, el sistema no parece alfabético, silábico, pictográfico o logográfico, pudiendo tener elementos de los últimos dos. Como diagramas, estos diseños exhiben marco de relaciones que no son conmensuradas con declaraciones fonéticas, es difícil configurarlos en palabras.

Los define como semasiográficos en tanto que representan grafemas, citando a G. Sampson (1985) quien reconoce la posibilidad abstracta de que los sistemas semasiográficos puedan ser expandidos hasta convertirse tan complejos y ricos en potencial expresivo como el lenguaje hablado.

\section{Dimensión tiempo y espacio}

Pino Matos (2014) propone que la existencia de algunos diseños geométricos, conocidos como tocapu, podrían estar haciendo referencia a fechas importantes del calendario inca, las que se encontrarían representadas en una arquitectura planificada y vinculada con el paisaje sacralizado de Huánuco, con dibujos de casana que en trajes rituales reproducían festividades de agosto el comienzo de la labranza (ejemplo manto calendario analizado por Urton fig 17). Ver posición de los colores y esquema del manto calendárico MFA325 (Urton 2007: 255-257 fig 17).

Al comparar la organización del espacio del manto calendárico MFA325 que analizó Gary Urton (ibid), podemos observar que este manto, gracias al uso de los colores rojo, amarillo y una combinación de los anteriores con el azulverde presenta una configuración del espacio de forma bidimensional muy similar al diseño de la construcción cuatripartita de Huánuco Pampa.

Indicando además que los diseños escalonados de las túnicas se han plasmado en la arquitectura de piedra, en la de barro, diseñaron y plasmaron conceptos e identidades arquitectónicas.

Makowski (2010) expresa que es posible que las composiciones que se plasmaron en textiles y en arquitectura, efectivamente, reflejen la idea de un orden natural y social, que organiza el universo en divisiones de dos mitades, o en cuatro suyus y que cada mitad y sus partes correspondan a tiempos del ciclo anual.

Referente a la noción tiempo y espacio en los tocapus estudiada por Zuidema (Códigos del Tiempo 2015), comparando almanaques cuádruples en túnicas comprobó que eran similares. Trátase de tocapus producidos por distintas culturas, incaica, huari y tihuanaco, y también nasca y moche.

Indica que el espacio es visible a través de la cultura material pero el tiempo es acción y es ahí cuando el calendario organiza las actividades de las gentes en patrones reconocibles(íbid).

En esa concepción de tiempo y espacio relacionados, la meta era comprender todas las figuras y diseños en las túnicas analizadas. Y cita a Young Sanchez (2004) referida a la Túnica de la Portada describiendo "que codifica mensajes sociales, políticos y religiosos dentro de una representación idealizada de la misma ciudad de Tiwanaku”.

\section{Los tocapus en Llullaillaco}

"Hase de advertir que todas las más guacas, fuera de sus haziendas, tienen bestidos de cumbe que llaman capaccochas del grandor de las guacas. Y lo primero que se ha de procurar es estas capaccochas porque, quedando en su poder, tornarán a bestir la piedra que quieren, de manera que no quede reliquia de la tal guaca."

(Un inédit de Cristobal de Albornoz,

Duviols P. 1967)

Elena Phipps (2017) al desarrollar el tema de los textiles en los ritos andinos, nos indica que los incas crearon textiles especiales, a veces tejidos al tamaño y forma para envolver los objetos rituales: pequeñas figuras de oro, plata y spondylus envueltas o vestidas de textiles, que contribuyen al valor de ofrendas a Yllapa (dios del rayo) en entierros sacrificiales de altas montañas.

Ann Peters (2015) afirma que las prendas en miniatura fueron modeladas a partir de características estéticas y técnicas usadas por las Coyas y mujeres especiales llamadas acllas, iguales a las prendas textiles de tamaño completo. Se refiere a piezas arqueológicas, documentadas provenientes de los sacrificios de niños capac hucha en las cumbres nevadas de las regiones de Qulla Suyu y Kunti Suyu.

Dice:

"Los niños que han sido estudiados no son incas étnicamente en origen, que han ofrecido a sus hijos e hijas como parte de relaciones de intercambio, anudando una red de alianzas políticas 

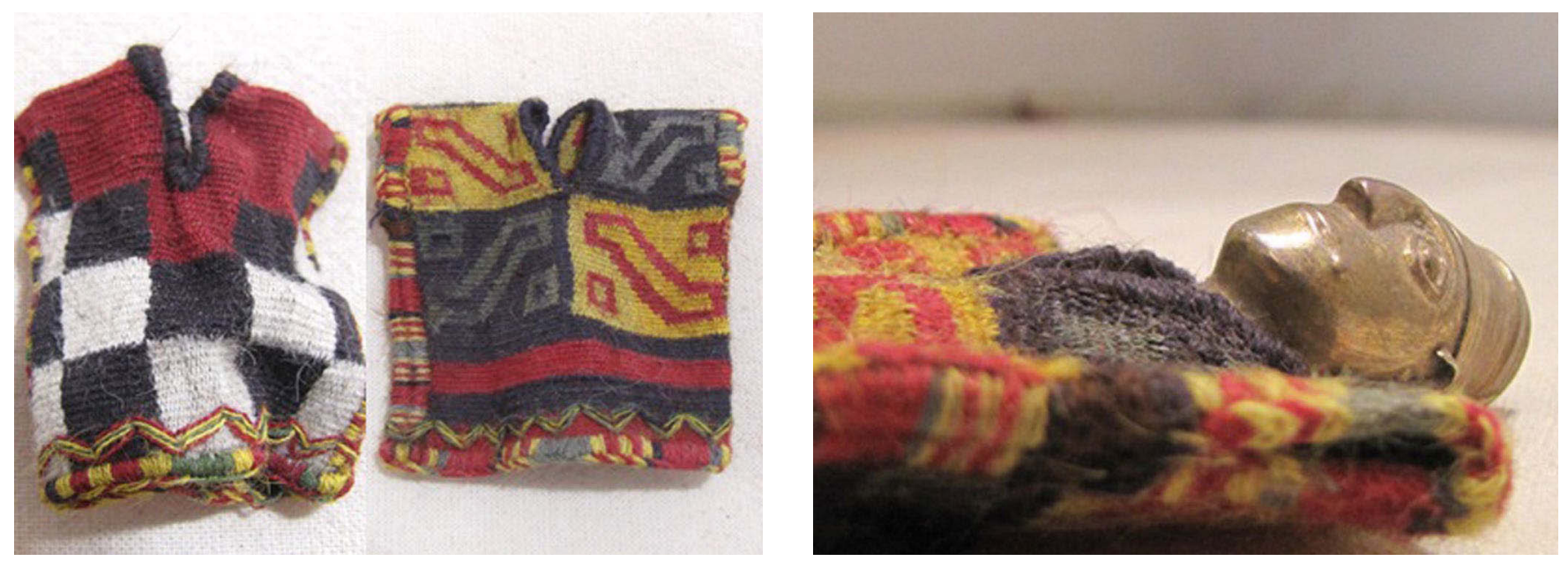

Figura 8a y 8b. Textiles en miniaturas en el ajuar de Llullaillaco, visten pequeñas figuras antropomórficas. Archivo MAAM Salta Argentina

que crearon y mantuvieron el imperio. Los niños usan vestimenta regional y tienen túnicas incas emblemáticas u otras prendas en la parte superior o dobladas y colocadas al lado (en Reinhard y Ceruti 2000; Schobinger 2001)."

\section{(Ann Peters ( ibid )}

Algunas prendas son honoríficas u ofrendas, ya que pueden ser del tamaño incorrecto para los niños hallados; figuras femeninas y masculinas en miniatura se colocan cerca de los sacrificados junto a otras ofrendas.

Estos entierros sacrificiales, conservados en condiciones glaciares se acercan más a la descripción de los mallquis incas. (ibid)

En distintos hallazgos, uncus, túnicas, fueron colocados junto a la ofrenda humana, éste es el caso de la Doncella, cuyo tucapu se halló doblado sobre el hombro.

Frecuentemente son de tipo estándar, incluso los podemos encontrar representados por uncus en miniatura en la que figuras masculinas de oro, femeninas de plata o spondyllus, están vestidos y que acompañan a las momias (ajuar).

Zuidema (1991) expresa que solamente los incas del linaje del primer rey, Manco Cápac, se muestran usando los diseños de tucapu. La característica de élite que no se repite en túnicas comunes fue el tejido con diseño de tapicería que define al tocapu, este rasgo distintivo se reservó solamente para las túnicas clásicas de élite, de las familias reales o de oficiales imperiales.

Mary Frame (2007) nos indica que el patrón llamado llave inca es una clase bien definida de túnica que alterna dos variantes de la llave inca con diseño tocapu en un patrón de tablero de ajedrez en la parte superior con la sección inferior que exhibe amplias bandas (seis) en dos colores alternantes.
Se han hallado en la costa del Perú, como indicativo de que fueron obsequiadas por el Inca a los dignatarios en las provincias costeras.

Se cree que manifiesta un mensaje gráfico de la organización Inca cuando la pieza de forma rectangular, concebida desde su elaboración como una unidad, reproduce:

- diseño conocido como damero, formado por 80 cuadrados, conteniendo cada uno de ellos el motivo de la llave inca.

- presenta dos variantes en las propiedades de la dirección y el color: una llave luminosa/brillante (rojo sobre amarillo) con una orientación y una llave oscura/opaca (azul/verde) con la orientación opuesta.

- cuatro colores que son usados invariablemente y dos de los cuatro colores son repetidos en las bandas de la mitad inferior de la túnica

- las costuras lateral y aberturas para los brazos están cosidas con rayas perpendiculares de distintos colores al igual que el orillo inferior de la túnica, con un diseño de rayas de tres colores formando un zigzag horizontal continuo por encima del orillo del ruedo.

Frame (2007) define llave inca como un diseño de simetría finita, con rotación. Indicando que el intervalo de rotación es denominado "doblado dos veces", siendo congruente consigo mismo en solo dos puntos en una rotación circular completa.

Pertenece a una clase de diseños denominados curvas invertidas, porque los dos finales tienden a ir en direcciones opuestas o inversas.

Estas curvas invertidas son zoomorfizadas como serpientes de dos cabezas, pueden verse más austeras geométricamente como las letras $\mathrm{Z}$ o $\mathrm{S}$. 


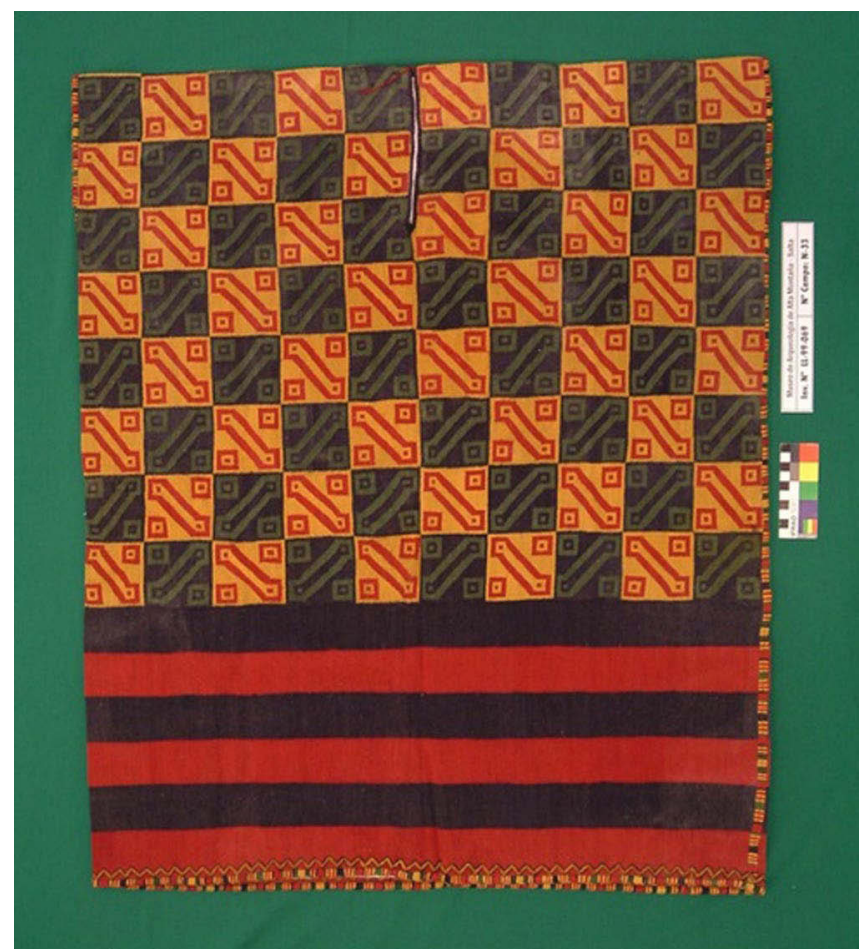

Figura 9. Uncu tocapu motivo llave inca encontrado doblado En el hombro derecho de la doncella. MAAM Salta Argentina.

Otros modos de discurso, aparte de los códigos gráficos textuales, enfatizan el patrón de figura de ocho y su ciclicidad alternada.

Es necesario recordar que el nudo khipu que denota el entero uno es un nudo en figura de ocho, usado también en los preparatorios para tejer, cuando se ordena la urdimbre,
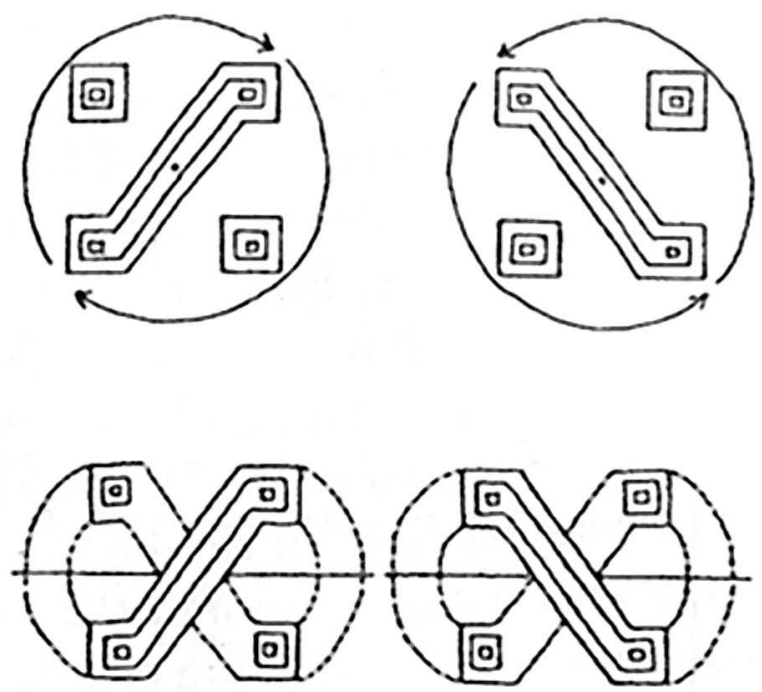

Figura 10. Dibujo Mary Frame (2003).
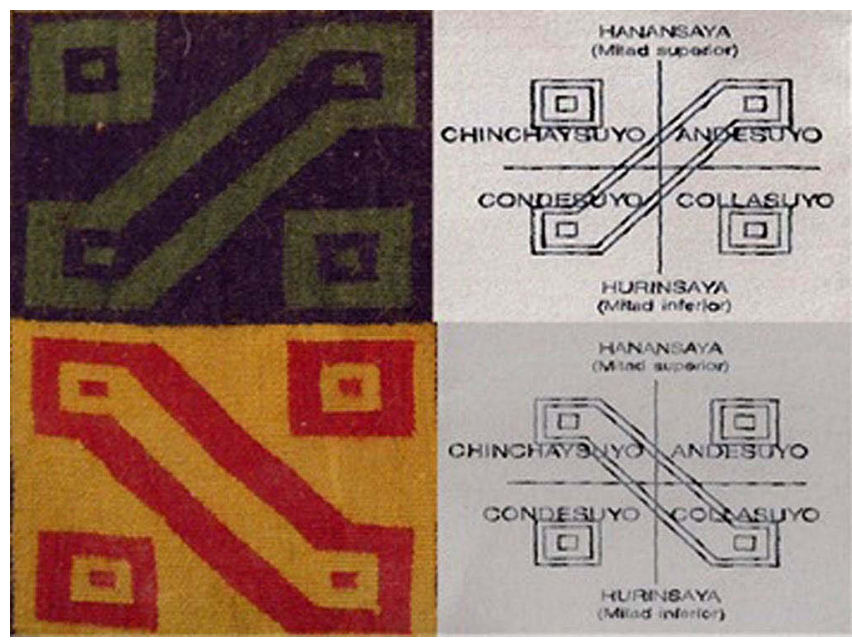

Figura 11. Cuadro realizado por B. Carbonell usando el ideograma de Mary Frame (2003) en tocapu de LLullaillaco

porque mantiene la urdimbre sin enredos, pero además intercala alternación binaria (arriba-abajo) con orden secuencial (corriendo de izquierda a derecha).

La misma ciclicidad alternada se señala en la estructura socio-política Inca, donde una de las secuencias jerárquicas de los cuatro suyus intercala una alternación binaria entre fracciones la secuencia de los suyus (ibid.):

\section{Chinchaysuyu (hanan) \\ Collasuyu ( hurin) \\ Andesuyu ( hanan) \\ Condesuyu ( hurin)}

Puede inferirse que al usar tales túnicas los dirigentes de las provincias conquistadas o asimiladas al Imperio imponían su posición en el nuevo orden y al mismo tiempo se conformaron con los nuevos niveles de autoridad del Estado que invalidaba su anterior autonomía y aceptando la autoridad del Inca.

\section{Considerando}

- que el uncu constituyó el elemento por excelencia de la indumentaria masculina incaica y que fue hallado entre el ajuar de una joven aclla

- en el hombro derecho de la doncella, prolijamente doblado, manifestando la pertenencia heráldica a alguna clase de jerarquía

- estas túnicas fueron utilizadas para extender una iconografía oficial del Imperio, con fin de consolidar una cohesión política, social, económica y tal vez religiosa. 


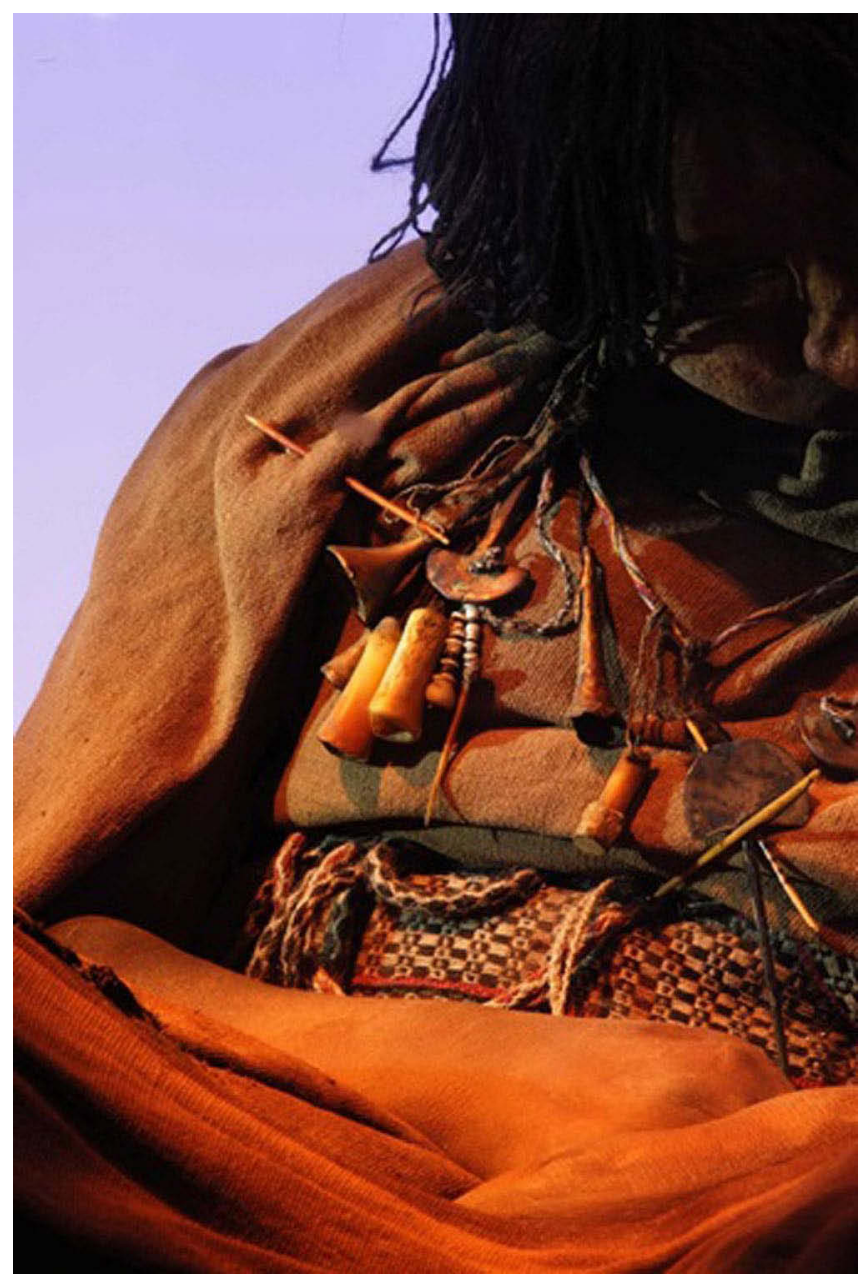

Figura 12. Fotografía Archivo Museo MAAM, vestimenta y parafernalia de la Doncella.

Ceruti (2015) y otros autores afirman que las túnicas finas fueron enviadas como regalos diplomáticos por los incas a los líderes locales o curacas. Los curacas a menudo tuvieron papeles importantes en las capacochas, incluso ofreciendo a sus propios hijos, según lo informado por los cronistas (Hernández Príncipe [1621] 1986).

Sería ésta la razón por la que se enterraron finas túnicas masculinas junto a las ofrendas femeninas en Llullaillaco y en otros lugares (Reinhard y Ceruti 2000)

\section{Vestía acsus color café:}

Este antiguo vestido femenino consistía en una gran tela cuadrada (ajsu) usada como falda, faja policroma enrollada a la cintura, por medio de la cual la tela era colocada en su sitio.

El ajsu se usaba sobre la piel, desde el costado derecho se envolvía en torno del cuerpo, cubriéndolo desde los hombros hacia abajo y desde las caderas hasta los pies (Cieza de Leon 1986 [1563] cap. 41), dejando libres los brazos. Se suspendía de ambos hombros por agarres.

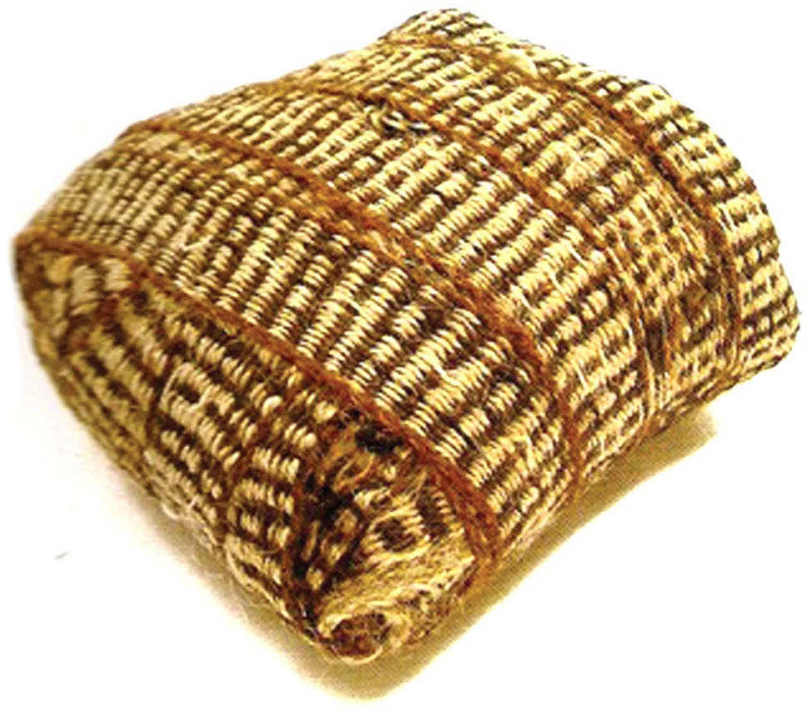

Figura 13. Faja tejida sujetaba el acsu de la doncella. Archivo MAAM Salta Argentina

El "cinturón madre" o mamachampi, pequeño, y de tejido grueso se usaba sobre el ajsu ajustando y dando forma a la cintura.

La faja policroma de tejido atrayente y enteramente largo, llamado chumpi

El manto lliclla, de color grisáceo, de forma cuadrada usada en torno del ajsu, por encima de los hombros se sujetaba por el pecho con un objeto llamado tupu o alfileres topo, de metal.

El color grisáceo comparado con textiles antiguos aparece como un nuevo color, tanto en lana como matiz natural y en algodón como tinte artificial, añadiéndose que sólo aparece durante el período incaico en textiles de la cultura costeña, apareciendo como introducido por contacto con la civilización de Cuzco.

Colgantes de hueso y tupus de metal completaban los objetos que adornaban a los niños; otorgándoles pertenencia a distintas regiones del territorio inca.

Textil color canela envoltorio externo y otro textil de color semejante cubriendo cabeza y parte superior del cuerpo:

Las túnicas de color canela presentan gran interés cuando como las túnicas clásicas se tejieron de un solo paño largo y muestran dimensiones más largas que anchas (1.40 × 1.45).

Se ha usado la técnica de cara de urdimbre y no de trama, han sido encontradas en gran número de ejemplares en sitios de la costa sur del Perú, sugiere su uso como una forma de distinguir a los funcionarios que servían al Inca. 
Las prendas de color castaño fueron usadas sólo por mujeres del rango de los altos jefes o funcionarios.

Cuatro ideas distintivas se representaban en los colores con que se vestía a las mujeres:

$1 \mathrm{El}$ sol : blanco correspondía a la yuraj ajlla

2 El Inca : roja correspondía a la wairuru ajlla

3 La provincia: castaño correspondía a la p'aqo ajlla

4 El jefe y el pueblo común: negro correspondiente a la yana ajlla

Santacruz Pachacuti Yampi (1879[1620-1630) escribe que "Inca Tupac trajo de sus campañas muchas mujeres jóvenes, principalmente las doncellas escogidas (ajlla) para Tiksi Qhapaj Wirqocha Pachayachachij, llamadas Yuraj ajlla"

"Había hecho construir casas para las cuatro clases: yuraj ajlla, páqo ajlla para los caciques (los apukurakas) y la Yuna ajlla para los indios comunes".

Fray Ramos Gavilan (1976 [1621] confirma claramente que las acllas wairuru, turaj y p' aqo eran sacrificadas al Sol.

Santacruz Pachacuti Y (1879) expresa que las yuraj ajlla y p'aqo ajlla estaban destinadas a los apucuracas quienes eran los encargados de seleccionar en el Imperio a todas las niñas que luego serían distribuidas en las acllahuasi.

Fue hallado en el ajuar de la Doncella, con las agujas e hilo pespunteando el borde, lo que nos permite suponer que su tarea de aclla continuó hasta el momento de ser ofrendada finalmente en altura.

Las muestras analizadas en laboratorio demuestran que se trata de una manta de lana de camélido. Tejida con técnica de faz de urdimbre presenta forma rectangular,

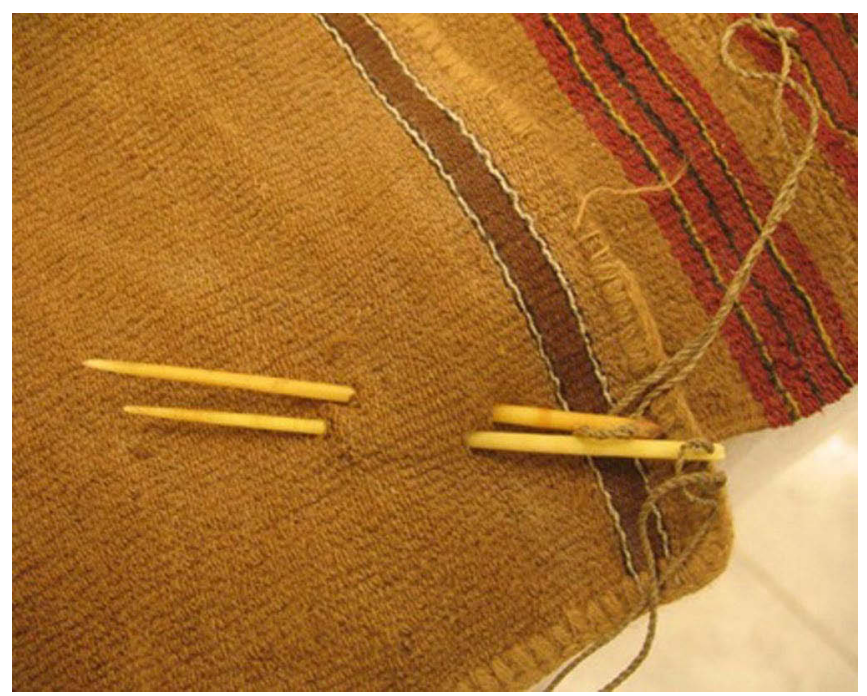

Figura 14 Textil con agujas de cardón que perteneció a la doncella en plena función de terminar los bordes mientras proseguía el ascenso al Llullaillaco. Archivo Museo MAAM. decorada con listas laterales predominando colores naturales (canela, ocre, natural) rojo y negro.

Cumplía una función ritual al envolver el cuerpo ofrendado, las agujas de cardón servían para realizar la terminación en las orillas que quedaran de modo inconcluso al ser sacrificada.

\section{Chuspas tejidas y plumas}

Las chuspas en Llullaillaco presentan características de tejido del Período Horizonte Tardío, de tamaño mediano, utilizadas para los rituales, conteniendo pigmentos de colores, plumas de color rojo, hojas de coca y otros elementos rituales.

Las bolsas de menor tamaño llamadas wayuña (de $10 \times$ $10 \mathrm{~cm}$ a $7 \times 7 \mathrm{~cm}$ de promedio) de forma cuadrada o rectangular, con superficie lisa o listada cumplían la función de contener hojas de coca, harina, maiz e implementos textiles.

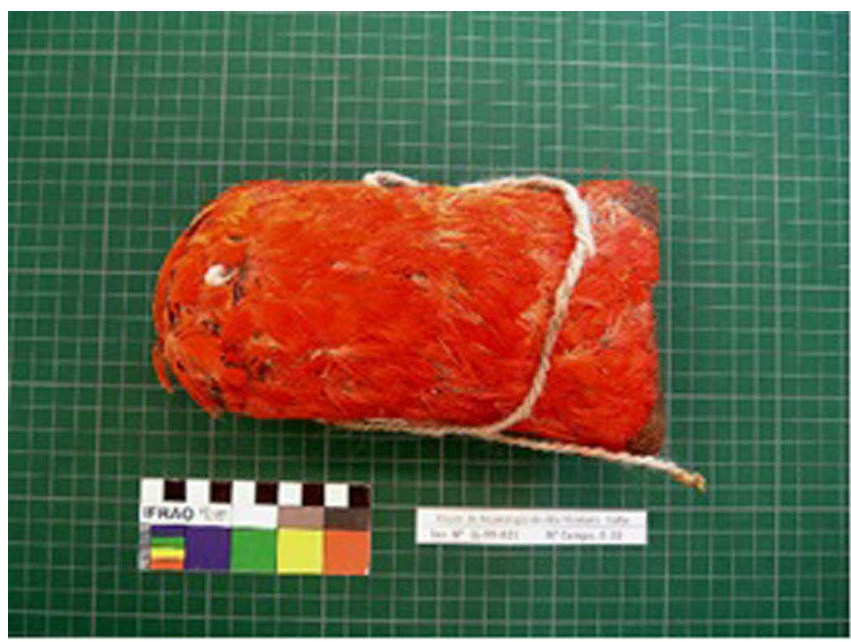

Figura 15a. Bolsa tejida cubierta con plumas rojas

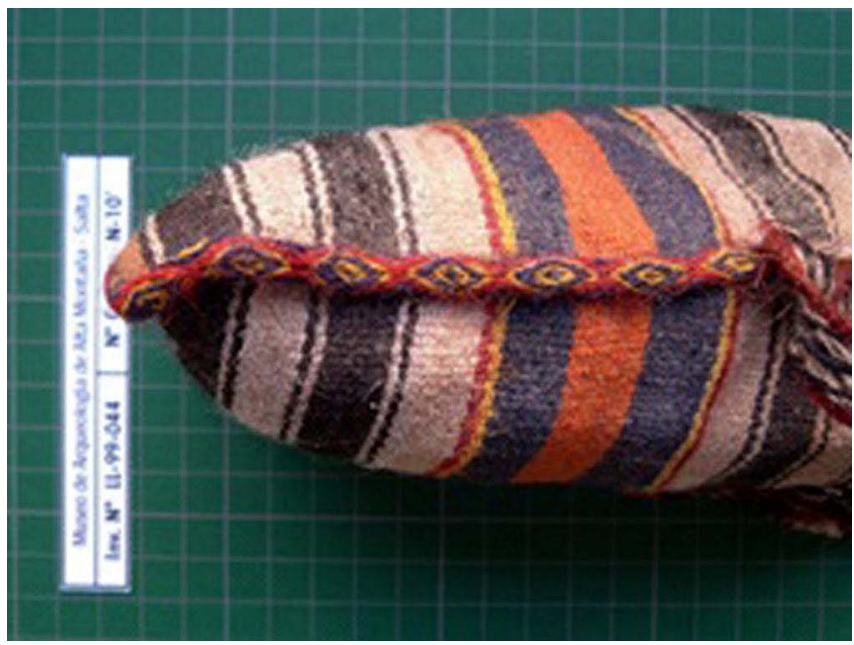

Figura 15b. Bolsa tejida con borde de diseño diamante Archivo Museo MAAM. 
Presentan mayores refuerzos en los bordes y orillas con festón anillado simple, las tiras son más gruesas, tejidas en telar y se observan diseños geométricos en franjas horizontales.

Disminuyen la cantidad de motivos haciéndose más comunes los motivos geométricos simples: la letra $\mathrm{Z}$ en sucesión vertical, ganchos en miniatura, etc.

Se utilizan colores naturales preferentemente, reservando los colores teñidos (gama limitada) para las franjas.

La aplicación de plumas en bolsas y mantos textiles ha sido bien documentada en las ofrendas en Llullaillaco, ya que se colocó una chuspa o bolsa cubierta de plumas rojas y presumiblemente que contenía hojas de coca en el entierro de la niña más joven, mientras que una bolsa de plumas blancas similar fue enterrada en asociación directa con el niño.

Encontramos en la bolsa con rayas horizontales, en su borde un diseño de tocapu diamante; con marco en forma de diamante y un centro de la misma forma.

El diseño diamante se produce en una amplia gama de variantes, con marco y sin marco en túnicas y otros artefactos, siendo recurrente en túnicas y textiles hallados en las zonas costeras lejos del centro del imperio inca.

Las bolsas chuspa en el Período Intermedio Tardío contienen sólo hojas de coca, las tiras o soguillas son acordes con el diseño general de la pieza, presentando sólo trenzado o cuerdas; es el Período Tardío cuando su contenido se amplía y varía desde hojas de coca a plumas, pelos, y otros.

\section{Spondylus yllas y collares}

Llamada mullu, fue singularmente apreciada por los incas considerándola un material más valioso que el oro.

Fue alimento simbólico de lugares sagrados elemento preferido para las huacas (Taylor 1999).

Rosing (1996) describe que el uso e importancia del spondylus permanece hasta el presente.

Este collar en particular con tejido de fibra de camélido y cabello humano, color negro es similar en formato a otros objetos hallados en culturas como Nasca (Museo Antonini Cahuachi) y en otros hallazgos de preincaicas.

Figuras en spondylus, miniaturas vestidas con tejidos cumbís, llamas talladas, acompañaban el enterramiento de Llullaillaco.

Reinhard y Ceruti (2010) sostienen que las miniaturas del Llullaillaco no son sacrificios sustitutivos ya que fueron enterradas junto a las ofrendas humanas y no en lugar de ellas.

Es probable que en la mayoría de los casos las estatuillas masculinas y femeninas representaran deidades asociadas con el volcán y otras montañas de la región (en Mignone 2015).

En algunas estatuillas de plata se encuentran adornos de spondylus en las terminaciones de los tejidos delicadamente y en miniatura completan el vestuario con diseños cumbís.

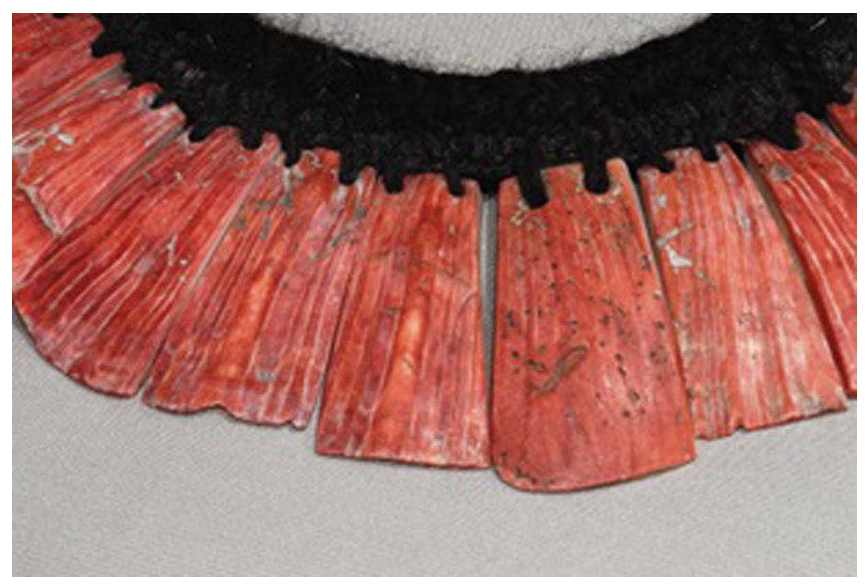

Figura 16a. Collar de spondylus hallado en el ajuar del niño engarzado en textil de lana negra y cabellos.
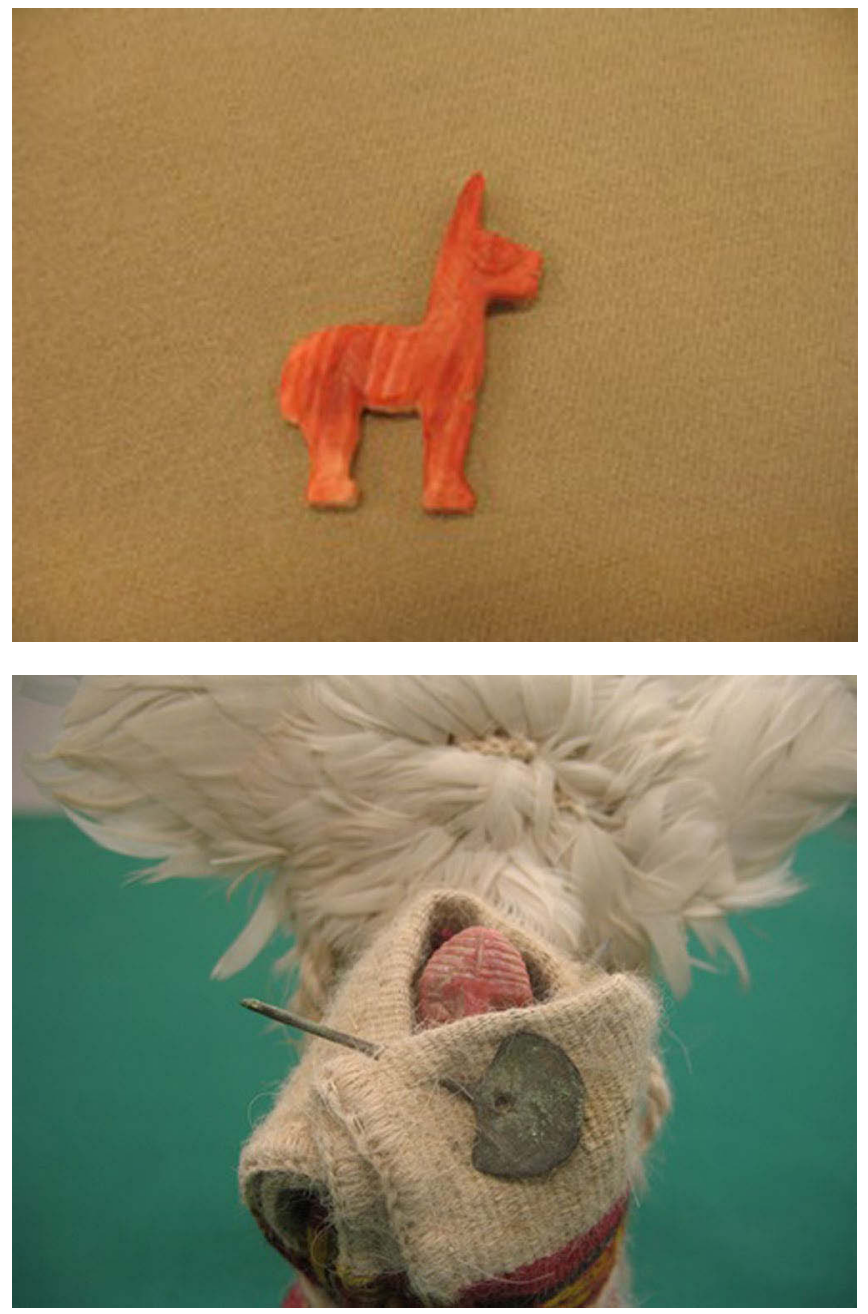

Figura 16b. Pieza camélido esculpida en spondylus. Figura 16c estatuilla de spondylus totalmente vestida con tupu y tocado de plumas blancas. Archivo Museo MAAM Salta Argentina 

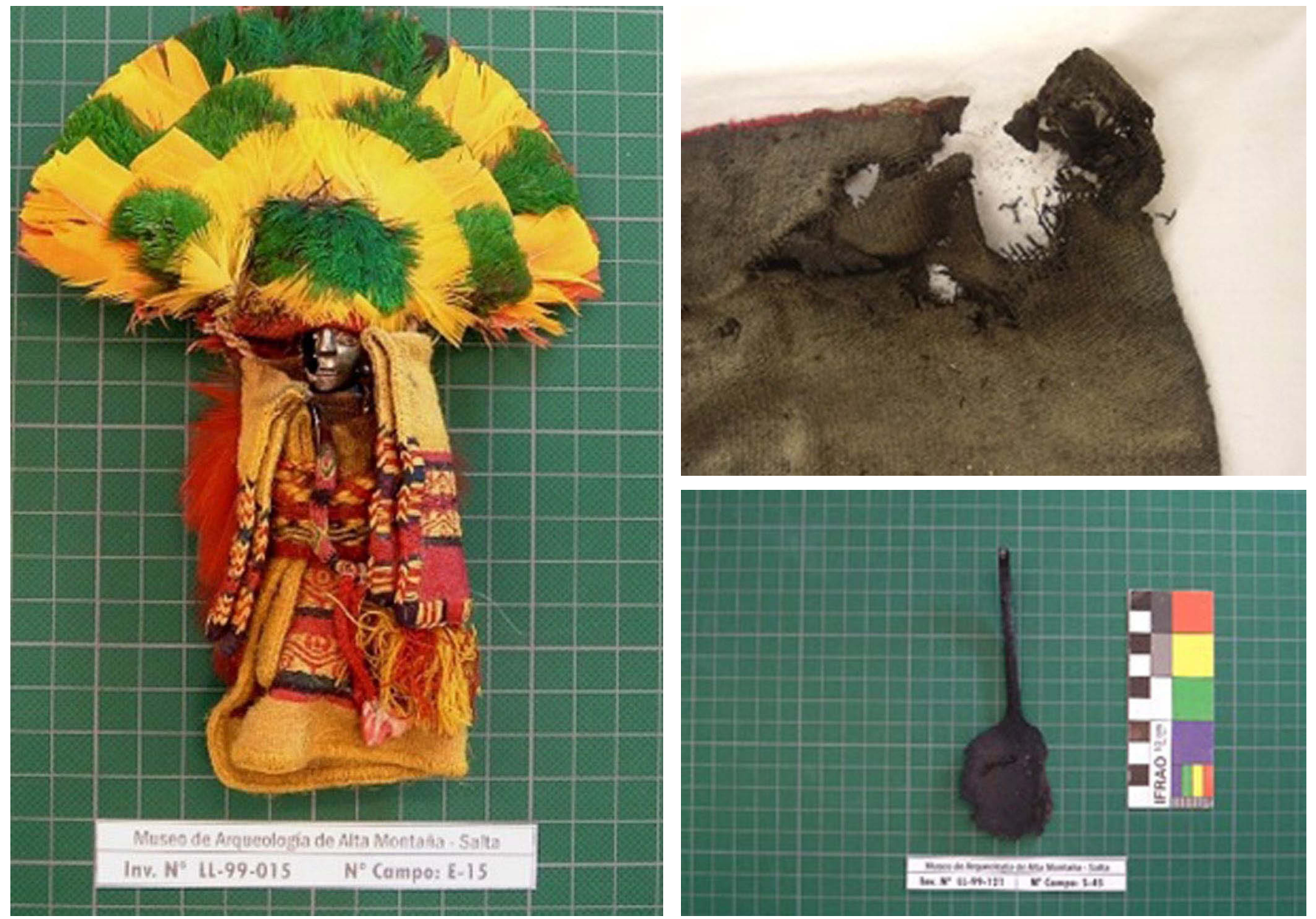

Figura 17 alcanzados por el rayo pertenecen al ajuar de la niña del rayo. 17a figura de metal con la cara quemada por un rayo; 17b gorro de la niña quemado por un rayo que alcanzara su cabeza; 17c tupu quemado por rayo. Archivo Museo MAAM Salta Argentina

También se hallaron conchas de spondylus junto a otros enseres del ajuar.

Los colores como el blanco, el rojo y el azul-negro, presentan guardas amarillas geometrizadas, signos utilizados en tucapu, se trata de guardas y dibujos finamente combinados, que han sido reproducidos en cerámicos y en madera en otro contexto y regiones.

Polo de Ondegardo (1916) describe al Dios del Trueno como el Hondero celestial

“[...] el trueno [...] es vn hombre que está en el cielo con vna honda y vna porra, y que está en su mano el llouer y granizar, y tronar [...]"

Las ofrendas y sacrificios al dios Illapa se daba en regiones de altura; en este caso la niña del rayo fue alcanzada por una descarga que quemó parte de su cara y gorro cefálico, tupu y prendas.

Junto a los niños fueron halladas hondas de cuero y lana; y curiosamente la niña del rayo tenía en su frente un adorno de metal, que sin duda atrajo al rayo que quemara su rostro y pertenencias.

Las túnicas comunes de Horizonte Tardío comparten con los ejemplares de las túnicas pertenecientes a la élite Inca un grupo de características, esto se debe a que las túnicas de élite sirvieron de modelo básico, estandarizadas en su forma, en el tejido, costuras de unión y de remates.

Se cree las rayas y bandas sin tocapus en los textiles pertenecían a los oficiales no Incas, Zuidema observa que las rayas o bandas verticales aparecieron en las túnicas de los oficiales de los cuatro suyus del Imperio, fuera del Valle de Cuzco.

Otra característica muy visible es que fueron tejidos con un tamaño mayor en el largo que en el ancho, fueron textiles que muestra una cara de trama muy fina que incluye diseños de tapicería geométrica, tejidos en un solo paño, incluyendo la abertura para el cuello.

Las costuras de unión por los lados son de listas y barras policromas en rojo, amarillo y otros colores contrastantes, rematados alrededor de la parte inferior y en las aberturas 
con puntadas de anillado cruzado con hilos de los mismos colores, bordeados con puntadas en forma de zigzag visibles en la parte inferior.

La fila de zig zag aunque no fuera un tucapu demuestra el status de élite de quien la vestía.

La túnica que vestía al niño es de color rojo puro, con algún detalle en azul, E. Phipps (2017) referido a los tintes dice que los pigmentos rojos parecen estar entre los primeros colorantes y asociados con espacios rituales.

\section{Consideraciones finales}

Se puede inferir que este hallazgo se enmarca en la ceremonia de capac hucha durante un ritual de ofrenda humana y de objetos de carácter real, destinados a las altas cumbres.

Así lo determinan las características de este sacrificio similar a otros en montañas cercanas.

\section{Respecto a la datación:}

Reinhard me escribe: "en ese entonces no hicimos un examen del C-14, pero olvidé que si lo han hecho en Gran Bretaña. Como escribí en el libro que estamos publicando sobre Llullaillaco (Reinhard and Ceruti 2010): "A calibrated accelerator mass spectrometer (AMS) radiocarbon (C-14) date obtained from the hair of one of the Llullaillaco mummies indicated she died between A.D. 1430 and 1520 (Wilson et al.2007:16,457), which is in basic agreement with the A.D. 1470 to 1532 time frame generally accepted for the Inca presence in northwestern Argentina."

Referente a Llullaillaco como guaca, dadas las condiciones de enterramiento en altas cumbres y la dificultad de ascender, podemos argüir que no constituyó este volcán una guaca a la que fueran ofrendados periódicamente otros niños, ni presenta condiciones de guaca a la que se le consultara como oráculo.

Creemos sí que fue elegida de manera preferencial, para elevar la ofrenda real a los dioses, pidiendo por el control político y económico del territorio, la fertilidad del ganado y la agricultura, por el bienestar del inca o ante algún fenómeno climático de trascendencia.

La transhistoricidad del tocapu está demostrada cuando puede expresarse en distintas épocas: inca, colonial, etc representando formas y diseños, geométricos y heráldicos, vinculados todos a la jerarquía del Inca.

Ann Peters (2015) define la condición de estos entierros conservados en montañas glaciarias cercanos a la descripción de mallquis, si bien los niños no están momificados sino conservados por el frío; sí existe en los envoltorios distintos tejidos superpuestos, todos significativos, que
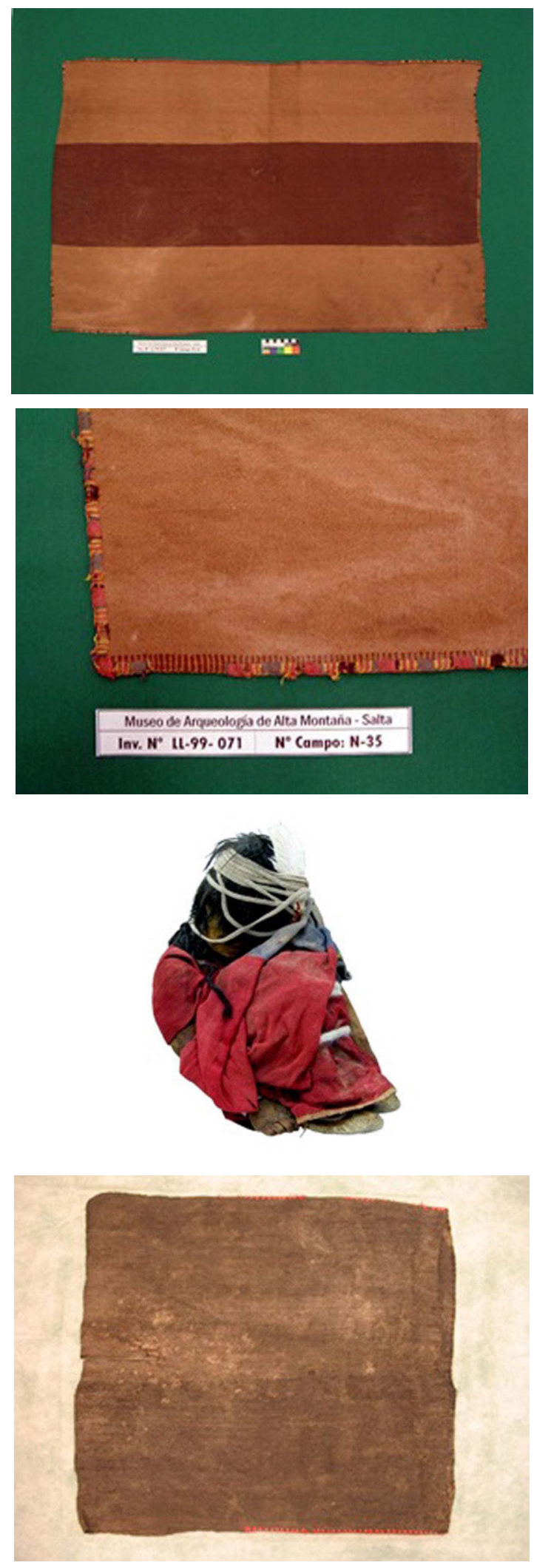

Figura 18. Túnicas en Llullaillaco: 18a Manto de la niña del rayo $\mathbf{1 8 b}$ Detalle de terminación y urdimbre del mismo; 18c Vestido rojo con detalles azul en el niño; 18d Uncu gris de uso exterior que cubría al niño. Archivo MAAM Salta Argentina 
envuelven, protegen y a la vez transmiten en sus tramas datos importantes sobre su identidad y genealogía cultural.

El reconocer calendarios en los tocapus instala una dimensión de tiempo y espacio que Zuidema (2015) ha relevado de manera magnífica, dejando abierto el camino para nuevos descubrimientos; puede leerse en los tapices la acción de perpetuar cogniciones anteriores que se repiten o se resignifican y que se reconocen como algo más que una narración estética; lo cual motiva descifrarlos porque incluyen implícito un legado.

E. Phipps (2017) preocupada por decodificar lo que sucede en el simple acto de tejer vislumbra una interrelación entre materiales y materialidad, cuando el proceso de fabricación de textiles transmite significado.

A través de los materiales, formulación de los hilos y estructuras del tejido, la articulación del diseño, su uso y contexto o en su materialidad se interconectan tradiciones técnicas con construcciones conceptuales (íbid).

Existe una relación primaria entre los textiles y la ceremonia, la piedra guaca o las illas, o las figuras antropomórficas, vegetales o minerales que dan color. Una mística que el tejedor experimenta y practica manipulando los elementos de hilar, agua, tierra, vegetal, mineral que lo convierten en creador comprometido.

La movilidad de los textiles ha permitido difundir técnicas y colores y modos de teñir más allá de la estandarización de las prendas; y todo ello vinculado con lo ritual.

$Y$ en esa acción de intermediarios entre los humanos y las deidades, los tocapus de Llullaillaco cumplen con la tarea de conservar, proteger, diferenciar y jerarquizar a los niños y objetos que visten.

\section{Referencias}

Carbonell Beatriz

2008 Fotografias de las fibras textiles del hallazgo de Llullaillaco.

2012 Registro exclusivo grabado en runa simi con fotografías propias, elaboración de cuadros comparativos. Informante Quispe en Paucartambo

2016 Memoria ritual en los textiles andinos Bariloche Argentina

Cerrón-Palomino, Rodolfo.

2008 Voces del Ande: Ensayos de Onomástica Andina. Lima: Pontificia Universidad Católica del Perú

\section{Ceruti Constanza}

1999 Cumbres sagradas del Noroeste Argentino. Avances en arqueología de alta montaña y etnoarqueologia de santuarios andinos Buenos Aires, Argentina: EUDEBA.
2003 Llullaillaco: Sacrificios y Ofrendas en un Santuario Inca de Alta Montaña. Publicación del Instituto de Investigaciones de Alta Montaña. Salta: Ediciones de la Universidad Católica de Salta.

2010 The religious role of children in the Andes - Past and Present AmS Skrifter; Lugar: Stavanger; Año: 2010 vol. 21/3 p. $123-131$

2015 Inca Offerings Associated with the Frozen Mummies from Mount Llullaillaco S onderband/Special Edition Perspectives on de inca I 2015. International Symposium from March 3rd to March 5th, 2014. Stuttgart

Cummins Thomas

1997 The Object of Imagery in Colonial Native Peru as seen through Guaman Poma's Nueva Corónica i Buen Gobierno. In: Journal of the Steward Anthropological Society, Volume 25, Numbers 1 and 21997

2004 Brindis con el Inca: La abstracción andina y las imagines colonials de los queros. Lima: Universidad Nacional Mayor de San Marcos, 2004. Print.

2011 Tocapu. What is it, What Does it Do, and Why Is It Not a Knot? In: Boone and Urton, Their Way of Writing. Dumbarton Oaks, Washington D.C.

De la Jara, Victoria,

1975 Introducción al estudio de la escritura de los Inkas. Lima: Instituto Nacional de Investigación y Desarrollo de la Educación.

De Rojas Silva, David,

1981 Los tocapu: un programa de reinterpretación. Arte y Arqueología 7: 119-132. Academia Nacional de Ciencias de Bolivia.

Duviols, Pierre

1967 Un inédit de Cristobal de Albornoz : La instrucción para descubrir todas las guacas del Pirú y sus camayos y haciendas, Journal de la Société des Américanistes Volume 56, Numero 56-1

Eeckhout, Peter y Danis Nathalie,

2004 Los tocapus reales en Guaman Poma: Una heráldica incaica? Boletin de Arqueologia PUCP Nro. 8

Frame, Mary

1994 Las Imágenes Visuales de Estructuras Textiles en el Arte del Antiguo Perú Revista Andina Año $12 \mathrm{~N}^{\circ} 2,2^{\circ}$ semestre: 295-372.

2005 What the Women Were Wearing: A Deposit of Early Nasca Dresses and Shawls from Cahuachi, Peru.

2007 Lo que Guaman Poma nos muestra, pero no nos dice sobre Tukapu Revista Andina Nro.44

2009 Tukapu, un código gráfico de los Inkas, Sistemas de notación inca : Quipu y Tocapu : actas del simposio internacional, Lima 
Fray Ramos Gavilan, Alonso

(1976 [1621]) "Historia de Nuestra Señora de Copacabana". Segunda edición completa. Academia Boliviana de la Historia, La Paz

Gentile Lafaille, Margarita

2009a Iconología del tocapu 119. Ponencia leída en las IV Jornadas de Arqueología Cuyana en homenaje al Dr. Juan Schobinger. Universidad Nacional de Cuyo.

2010 Tocapu: unidad de sentido en el lenguaje gráfico andino-Espéculo. Revista de estudios literarios. Universidad Complutense de Madrid

Gonzalez Holguin, Diego

2007 [1608] Vocabulario de la Lengva General de todo el Perv llamada Lengva Qquichua o del Inca”. Lima, imprenta de Francisco del Canto. (http://www.runasimipi.org) para publicación en el internet, 2007

Hernández Principe, R.

1923 [1622] Mitología Andina. Idolatrías de Recuay”. Lima 1986 [1621]. Idolatría del Pueblo de Ocros, cabeza desta comunidad. In Cultura Andina y Represión. Edited by P. Duviols, 442-448. Cuzco: Centro de Estudios Rurales Andinos, Bartolomé de las Casas.

Julien, C.

2000 Reading Inca History. University of lowa Press. lowa City.

MAAM Museo Arqueológico de Alta Montaña, Ciudad de Salta, Argentina

2007 Fotografías del Archivo del Museo Libro del Museo de Arqueología de Alta Montaña Edición 2007

Makowski, Krzysztof

2010 Vestido, arquitectura y mecanismos del poder en el Horizonte Medio, en Krzysztof Makowski (comp.), Señores de los Imperios del Sol. (Colección Arte y Tesoros del Perú), Lima:Banco de Crédito del Perú, pp. 57-72.

Mignone, P.

2015 Illas y allicac. La capacocha del Llullaillaco y los mecanismos de ascenso social de los "inkas de privilegio Museo Chileno de Arte Precolombino. Revista: Boletín del Museo Chileno de Arte Precolombino

Molina , Cristobal,

1989 [1573]Fabulas y ritos de los incas, en Los pequeños grandes libros de la historia americana 1ra. Serie 4 Lima

Murua, Fray Martín de

1616 Historia General del Perú, origen y descendencia de los Incas.
Ossio, Juan

2004 Códice Murúa: historia y genealogía de los reyes incas del Perú del padre mercenario Fray Martín de Murúa. Editores: Madrid Testimonio, España

Peters, Ann

2015 Visions of the inca dynasty. Narrative styles, emblematic dress and the power of ancestors tribus in Sonderband/special edición I, Perspectives on the inca pag 64-79

Phipps,Elena

2017 Andean Textile Traditions: Material Knowledge and Culture, Part 1 University of California, Los Angeles elena@ephipps.org

Pino Matos, Jose Luis

2014 El tocapu que narra el viaje del sol en el mes de agosto: la arquitectura inca como representación calendárica del orden . Una visión desde Huanuco Pampa. En Sistemas de notación Inca: Quipu y Tocapu. Lima 15-17 de Enero de 2009.

Polo de Odendargo, Juan,

1916 [1575] Informaciones acerca de la religión y gobierno de los incas, seguidas de las instrucciones de los concilios de Lima. En Colección de libros y documentos referentes a la historia del Perú tomo III Lima . Sanmartí y Cia.

Reinhard Johan and Constanza Ceruti

2000 Investigaciones arqueológicas en el volcán Llullaillaco: Complejo ceremonial incaico de alta montaña. Salta: EUCASA-Ediciones Universidad Católica de Salta

2006 [2005] "Sacred Mountains, Ceremonial Sites and Human Sacrifice Among the Incas.” Archeoastronomy XIX: 1 - 43. University of Texas Press. Austin.

2010 Inca Rituals and Sacred Mountains: a study of the world's highest archaeological sites. Cotsen Institute of Archaeology. LosÁngeles: University of California Press

Santa Cruz Pachacuti Yamqui, Juan

1879 Relación De Antiguedades deste reyno del Piru ( pp.242) Madrid publicada por Marcos Jiménez de la Espada.

Sampson, Geoffrey,

1985 Writing systems. A linguistic introduction, Stanford, Stanford University Press.

Schobinger, J. y Ceruti, C.

2001 Arqueología de alta montaña en los Andes argentinos. En Historia Prehispánica Argentina, editado por E.E. Berberián y A.E. Nielsen. Tomo U pp. 523-559. Editorial Brujas, Córdoba. 
Sherbondy, Jeannette,

1987 "Organización hidráulica y poder en el Cuzco de los Incas”. Revista Española de Antropología. Americana, 117.

Silverman, Gail

1999 Iconografia textil de Cusco y su relación con los tucapus incas en JA de Lavalle y

R. de Lavalle de Cardenas Ediciones. Lima

2015 Los signos del imperio: Tomo 1, La escritura pictográfica de los incas; Editorial Biblioteca Abraham Valdelomar Lima; Tomo 3 Capac Pallay: Lo invisible en el Tejido Andino, Editorial Biblioteca Abraham Valdelomar- Lima

Szeminski, Jan

1987 Un curaca, un dios y una historia Facultad de Filosofía y Letras UBA, MLAL, Jujuy

Urton, Gary

2007 "A Multi-Year Tukapu Calendar", en Clive Ruggles y Gary Urton (eds.), Skywatching in the ancient world. New perspectives in cultural astronomy. Studies in honor of Anthony F. Aveni. Boulder: University Press of Colorado, pp. 245- 268.
Ziolkowski, Mariusz S.

2008 Marco Curatola Petrocchi/ Mariusz S. Ziolkowski Adivinación y oráculos en el mundo andino antiguoColección Estudios Andinos IFEA- Lima

Zuidema, R. Tom

1991 Guaman Poma and the Art of Empire: Toward an Iconography of Inca Royal Dress In Cultural and artistic Encounters 151-202-

2011 Chuquibamba Textiles and Their Interacting Systems of Notation: The Case of Multiple Exact Calendars en Their Way of Writing, Pre Columbian America Elizabeth Hill Boone and Gary Urton editors

2015 Códigos del tiempo. Espacios rituales en el mundo andino. Apus Grhaps Ediciones. Lima Peru 